\title{
The Acquisition of Gender Agreement in Adult Learners of
}

\section{Arabic}

\author{
by
}

Ali Alamry

A thesis submitted to the Faculty of Graduate and Postdoctoral Affairs in partial fulfillment of the requirements for the degree of

Master of Arts

in

Applied Linguistics and Discourse Studies

\section{Carleton University}

Ottawa, Ontario

(C) 2014

Ali Alamry 



\begin{abstract}
The grammatical gender system is considered one of the most challenging structures that L2 learners must acquire. Part of this difficulty lies in the complexity of the system itself, and also from the fact that this system is one of the significant areas in which languages differ. Arabic is a language that has a rich grammatical gender system. It is comprised of two gender classes - masculine and feminine - that can be applied to nouns, verbs, adjectives and pronouns. The present study investigates the acquisition of subject-verb gender agreement in Arabic. The participants were adult L2 learners of Arabic with different native language backgrounds at two different levels of proficiency, as well as native speakers of Arabic. The participants were divided into three groups: the first group consisted of learners who have a grammatical gender system in their L1; the second group consisted of learners who do not have a grammatical gender system in their L1; and the third group consisted of native speakers of Arabic serving as a control group. One comprehension and three production tasks were used to elicit the data. The results from all tasks showed that none of the L2 learner groups performed as well as the native control group. Most importantly, there was no significant difference between the learners who have a grammatical gender system in L1 and learners who do not, suggesting no effect of L1. There was a significant effect of proficiency level; the advanced learners significantly outperformed the intermediate learners. The findings of this study are discussed in light of two different hypotheses regarding the availability of parameter resetting in L2 acquisition. These hypotheses are the Full Transfer/Full Access Hypothesis and the Failed Functional Feature Hypothesis. To some extent, the results lend support to the former hypothesis.
\end{abstract}




\section{Acknowledgments}

First and foremost, I must thank Allah, God the Almighty, as He is all and guides me through all.

I am also indebted to many others without whom this work could not have been possible. With the outmost respect and appreciation, I thank my supervisor, Professor Kumiko Murasugi, for inspiring and encouraging me, as well as for generously offering me her valuable time.

I am also eternally grateful for the continuous support of my beloved uncle, Abdulrahman, who has imparted me with a wealth of invaluable guidance throughout my academic journey. My most sincere gratitude extends to my family members and friends, and particularly my parents and my wife, who have showered me with endless love, encouragement, and prayers.

I also wish to recognize the Arabic Linguistic Institute at King Saud University in Riyadh, and those who welcomed me there, for their support, for the excellent facilities they made available to me, and for the overall opportunity to conduct my study there. I am equally grateful for the Arabic learners and native speakers who generously gave their time and agreed to participate in this study.

Last but not least, many thanks are owed to the SLALS faculty and staff at Carleton University, and especially Professor Lynne Young for her inspiration and support, as well as Joan Grant who graciously assisted me throughout the administrative process necessary to complete this project. 


\section{Table of Contents}

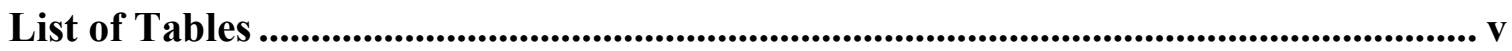

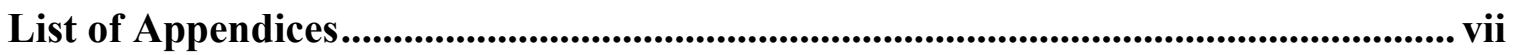

Chapter 1: Introduction ............................................................................................................. 1

Chapter 2: Second Language Acquisition: Language Transfer and Universal

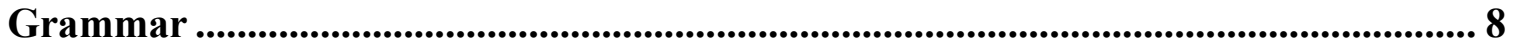

2.1 The role of $L 1$ transfer in second language acquisition ................................................ 8

2.2 Universal grammar and second language acquisition ..................................................... 12

Chapter 3: Language Acquisition and Grammatical Gender .................................. 20

3.1 Previous research on grammatical gender................................................................................ 20

3.2 Previous studies in Arabic ........................................................................................................... 24

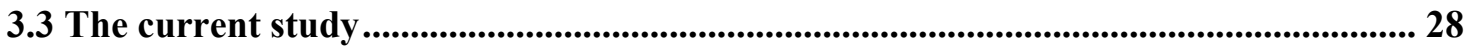

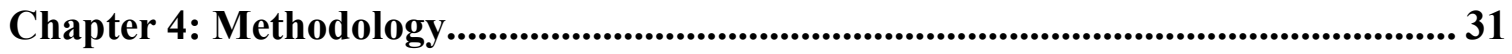

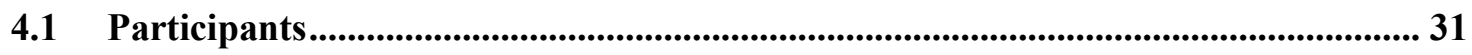

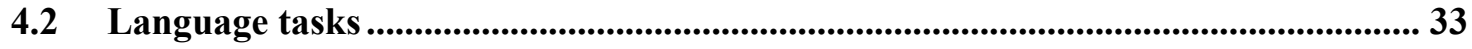

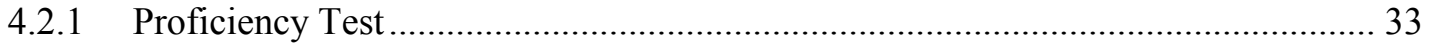

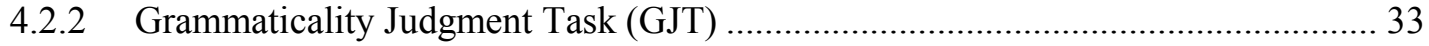

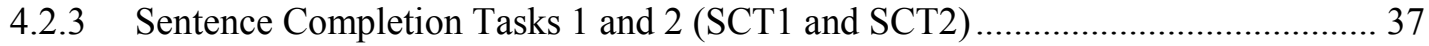

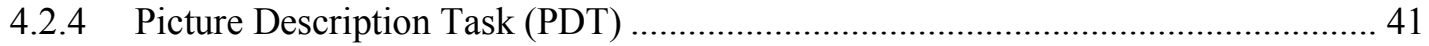

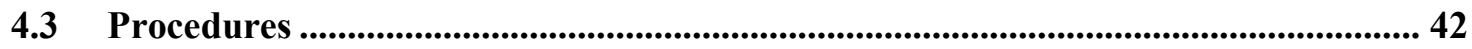

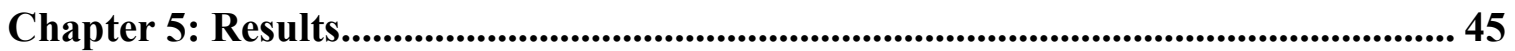

5.1 Proficiency Test ....................................................................................................................... 45

5.2 Experimental Tasks ............................................................................................................... 46

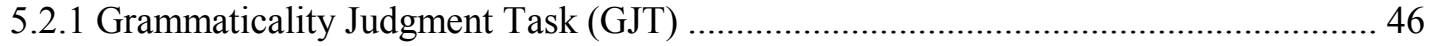

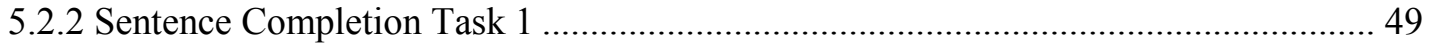

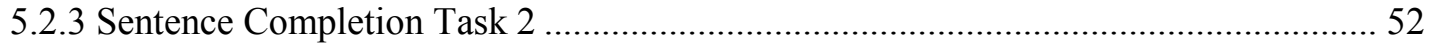

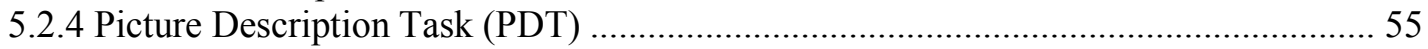

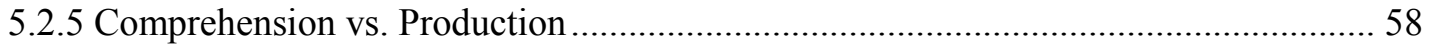


Chapter 6: Discussion ..................................................................................................... 59

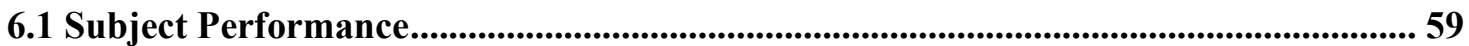

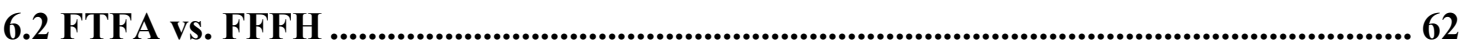

6.4 Learners' L1 ..................................................................................................................................... 68

6.5 Directions for further research .......................................................................................69

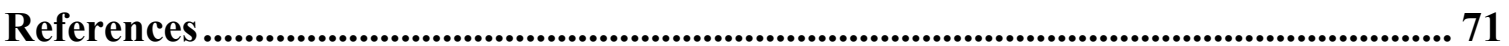

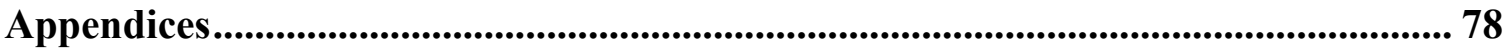




\section{List of Tables}

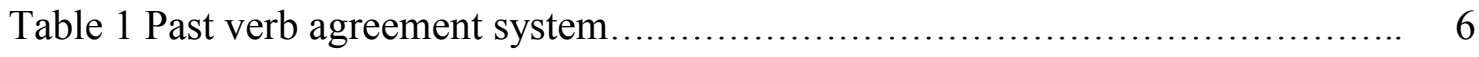

Table 2 Present verb agreement system....................................... 7

Table 3 Summary of transfer and UG access positions............................. 18

Table 4 Participant information................................................. 32

Table 5 Performance of Arabic learners and native speakers on the Proficiency Test 45

Table 6 Performance of the Arabic learners on the Proficiency Test by L1 gender

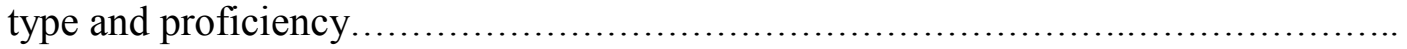

Table 7: Performance of the Arabic learners and native speakers on the Grammaticality Judgment Task

Table 8 Performance of the Arabic learners on the Grammaticality Judgment Task by L1 gender type and proficiency

Table 9 Performance of the Arabic learners on the Grammaticality Judgment Task by tense and grammaticality

Table 10 Performance of the Arabic learners on the Grammaticality Judgment Task by item type

Table 11 Performance of the Arabic learners and native speakers on the Sentence Completion Task 1

Table 12 Performance of the Arabic learners on the Sentence Completion Task 1 by L1 gender type and proficiency

Table 13 Performance of the Arabic learners on the Sentence Completion Task 1 by gender and tense features.

Table 14 Performance of the Arabic learners on the Sentence Completion Task 1 by gender feature and subject factors

Table 15 Performance of the Arabic learners and native speakers on the Sentence Completion Task 2 
Table 16 Performance of the Arabic learners on the Sentence Completion Task 2 by L1 gender type and proficiency

Table 17 Performance of the Arabic learners on the Sentence Completion Task 2 by gender and tense features

Table 18 Performance of the Arabic learners on the Sentence Completion Task 2 by gender feature and subject factors

Table 19 Performance of the Arabic learners and native speakers on the Picture Description Task.

Table 20 Performance of the Arabic learners on the Picture Description Task by L1 gender type and proficiency

Table 21 Performance of the Arabic learners on the Picture Description Task by gender feature.

Table 22 Performance of the Arabic learners on the experimental tasks.

Table 23 Percentage of participants who scored within the same range as native speakers on each task.

Table 24 Predictions of FTFA and FFFH with results of this study.................... 62

Table 25 The Arabic learners' performance on the experimental tasks................ 66

Table 26 The Arabic learners by L1 language family................................ 68 


\section{List of Appendices}

Appendix A Grammaticality Judgment Task ................................... 78

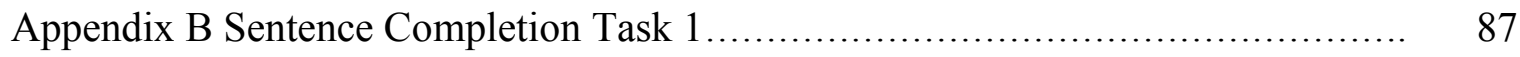

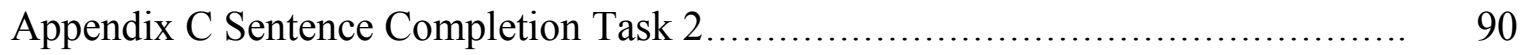

Appendix D Picture Description Task ....................................... 93

Appendix E Background Questionnaire ...................................... 97

Appendix F Participants' Results on Proficiency Test............................. 98

Appendix G Participants’ Results on Grammaticality Judgment Task ................. 99

Appendix H Participants' Results on Sentence Completion Task $1 \ldots \ldots \ldots \ldots \ldots \ldots \ldots \ldots . . \ldots 0$

Appendix I Participants' Results on Sentence Completion Task 2..................... 101

Appendix J Participants' Results on Picture Description Task........................ 102 



\section{The Acquisition of Gender Agreement in Adult Learners of Arabic}

\section{Chapter 1: Introduction}

A wealth of research has addressed whether second language (L2) adult learners are able to attain an equivalent level of proficiency as that of native speakers of the target language. While theories in L2 acquisition differ with regard to the extent to which L2 learners can reach native-like proficiency, shared among many of them is the attention they give to the role of Universal Grammar (UG) (Chomsky, 1965; 1980; 1981) in assessing L2 acquisition. For some SLA researchers, learners' first language (L1) is a key factor in mastering an L2; that is, postpuberty L2 learners are unable to incorporate grammatical features that are not present in their L1s. One of these grammatical features is gender agreement (Smith and Tsimpli, 1995; Hawkins and Chan, 1997; Tsimpli and Mastropavlou, 2007).

Grammatical gender is defined by Hockett (1958) as the "classes of nouns reflected in the behavior of associated words" (p.231). This system of noun classification is present in many languages throughout the world and absent in many others. Languages with gender systems may have two or more classes or genders; that is, a language may consist of masculine and feminine genders, or masculine, feminine, and neutral genders. In some languages, these classes of nouns can be based on semantic criteria, meaning that a noun can be assigned as masculine or feminine because of its meaning or one of its attributes such as biological sex, humanness, or animacy. In other languages, gender classification can be specified according to formal properties, so that a noun's gender is determined by its morphological or phonological features. Finally, in other cases, the 
noun-gender assignment is simply arbitrary. In most languages, noun classes are categorized based on semantic and formal criteria (Corbett, 1991). Gender is one of the grammatical categories that requires a process called 'agreement' or 'concord'. That is, the gender of a noun affects the form of other related words in the sentence; these related words differ among languages but they could be verbs, pronouns, adjectives, adverbs, determiners, and quantifiers, among others. Steels (1978) defines agreement as the following:

The term agreement commonly refers to some systematic covariance between a semantic or formal property of one element and a formal property of another. For example, adjectives may take some formal indication of the number and gender of the noun they modify (cited in Corbett, 1991, p. 105).

The acquisition of a second language's grammatical gender has been considered one of the most persistent problems that non-native learners face (Dewaele \& Véronique, 2001; Sabourin et al., 2006). In the current literature, there are a number of studies that have investigated this issue (White et al., 2004; McCarthy, 2008; Franceschina, 2001; 2002; Montrul et al., 2008), yet no consensus has been reached. In effect, there exist two conflicting views about whether L2 learners can ultimately acquire the grammatical gender of L2. The first group of researchers claims that gender and its features are functional categories that cannot be acquired in adulthood unless L2 learners have similar features in their L1 (Hawkins, 1998; Franceschina, 2001; 2002; Tsimpli and Mastropavlou, 2007). This view is in line with Hawkins and Chan's (1997) Failed Functional Features Hypothesis (FFFH), which states that linguistic properties and features that are not present in L1 fail feature checking in L2 acquisition. In contrast, other researchers provide empirical evidence suggesting that L2 learners are not restricted 
to their L1 grammar and can acquire the grammatical features of L2 regardless of their age, as well as their L1 (Slabakova, 2000; White et al. 2004; Bond et al., 2011). This view supports the Full Access/Full Transfer hypothesis (FTFA) (Schwartz and Sprouse, 1994, 1996), which claims that L2 learners have full access to Universal Grammar (UG) and have the ability to acquire all the linguistic properties and features that an L1 learner acquires. Although these studies provide different explanations and support various findings, they all agree that L1 transfer has a negative or positive effect on learning an L2 at least in the initial stages. The main difference between them is confined to the final outcome that L2 learners can expect to achieve.

The above two hypotheses and the various findings on grammatical gender acquisition upholding them motivated the present study to explore this issue in a new set of languages. While English, French, Spanish, Dutch, and Italian have received a great deal of attention in previous work (e.g. White et al., 2004; Franceschina, 2002; Sabourin et al., 2006; Oliphant, 1998), this study will examine the acquisition of grammatical gender agreement in Arabic ${ }^{1}$ by adult L2 learners from different L1 backgrounds that vary in their gender systems. Arabic is a language that has a rich grammatical gender system. It is comprised of two gender classes: masculine and feminine. ${ }^{2}$ It displays agreement with verbs, adjectives, adverbs, and pronouns. The masculine is the default base form, while the feminine form usually exhibits a suffix that indicates its gender. ${ }^{3}$

\footnotetext{
${ }^{1}$ Arabic in this study refers to the Standard Arabic.

${ }^{2}$ Sometimes a noun can be either masculine or feminine, such as sabiel (road), and souq (market).

${ }^{3}$ Not every feminine word has a gender marker. A number of words are feminine but have no suffix (proper name: Zaynab; crypto feminine: nafs, harb).On the other hand, a number of other words are masculine with a feminine suffix (Hamz-ah).
} 
There are three gender suffixes for feminine nouns: taa' marbuuta (-ah/ -at-un ${ }^{4}$; e.g.

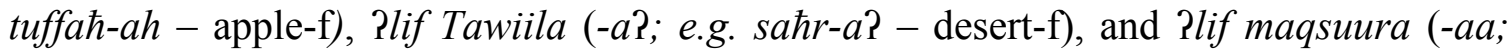
e.g. bushr-aa - tidings-f). The gender categories of nouns are classified based on: (i) natural gender, when a noun refers to human beings or animals (see 1 below), or (ii) formal gender, which is semantically arbitrary but gender-assigned to a noun according to its morphological form (see (2)).

(1) walad "boy.m"

bint "girl.f"

(2) $b a b \quad$ "door.m"

nafitha "window.f"

In example (1) it is clear that walad (boy) is assigned a masculine gender determined by biological sex. In (2), the noun nafitha (window) is marked as a feminine noun because it ends with taa' marbuuta (-a/ at-un), which is a feminine suffix as indicated above.

In Arabic, verbs are richly inflected and display agreement with the subject in person $\left(1^{\text {st }}, 2^{\text {nd }}\right.$ or $\left.3^{\text {rd }}\right)$, number (singular, dual or plural), and gender (masculine or feminine). This agreement differs according to the sentence word order, that is, whether it has a V S (verb subject) or S V (subject verb) order. In the case of V S order, the verb partially agrees with its subject in gender and person, but always takes the default singular form regardless of whether the status of its subject is singular, dual or plural ${ }^{5}$ (see (3)):

\footnotetext{
${ }^{4}$ There is no difference between $-a h$ and -at-un, as they both indicate the gender marker taa marbuuta. $-a h$ reflects the formal pausal pronunciation, (i.e. in case of a pause, a word like sayyar-at-un (car) would be pronounced sayyar-ah). This $-a h$ is referred to as $-a$ in some sources.

${ }^{5}$ In some Arabic dialects, the verb also agrees with its subject in number even in case of VS order.
} 
(3) a. kataba 1-muSallimu

wrote.3.m.s the-teacher.m.s ${ }^{6}$

'The teacher wrote'

b. kataba 1-muSallim-uun

wrote.3.m.s the-teacher-m.p.

'The teachers wrote'

The examples in (3) show that the verb kataba (wrote), which is in the third personal singular form, remains the same with the singular subject in (3a) and the plural subject in (3b).

In contrast, with $\mathrm{S} \mathrm{V}$ order the verb exhibits full agreement with the subject in gender, person, as well as number, as demonstrated in (4):

(4) a. 21-muSallim-uun katab-uu

the-teacher-m.p. $\quad$ wrote.3.m.p

'The teachers wrote'

b. P1-muSallimaa-tu katab-na

the-teacher-f.p. $\quad$ wrote.3.f.p

'The teachers wrote'

In (4a), the verb katab (wrote) agrees in gender and person, which is not morphologically apparent since the masculine agreement morpheme is null in the case of the third person.

\footnotetext{
${ }^{6}$ The following abbreviations are used in the glosses: $3=$ third person, $\mathrm{m}=$ masculine, $\mathrm{f}=$ plural, $\mathrm{s}=$ singular, $\mathrm{p}=$ plural
} 
It is also inflected by the number suffix (-uu) to agree with the plural subject $2 l$-muSallimuun (teachers). Similarly, in example (4b), the verb katab is inflected by the suffix (-na), which exhibits femininity and plurality, in order to agree with the feminine plural subject Pl-muSallimaa-tu.

Verbs in Arabic are inflected by means of prefixes and suffixes in order to agree with the subject in gender, number, and person. For gender agreement, verbs take the gender markers for masculine and feminine in the second and third person. The first person (I, we) is gender-neutral. In the past tense, the verb is inflected with a suffix that indicates all the agreement features, as shown in Table 1.

Table 1. Past verb agreement system

\begin{tabular}{|c|c|c|c|c|c|}
\hline Person & Number & Gender & Affix & Example & Gloss \\
\hline 1 & Singular & $\mathrm{M} / \mathrm{F}$ & $-\mathrm{tu}$ & $\hbar a d^{\complement} a r-t u$ & I attended \\
\hline 2 & Singular & M & - ta & $\hbar a d^{\oint} a r-t a$ & You (m.) attended \\
\hline 2 & Singular & $\mathrm{F}$ & $-\mathrm{ti}$ & $\hbar a d^{S} a r-t i$ & You (f.) attended \\
\hline 3 & Singular & M & $-\varnothing$ & $\hbar a d^{S} a r$ & He attended \\
\hline 3 & Singular & $\mathrm{F}$ & -at & $\hbar a d^{\natural} a r-a t$ & She attended \\
\hline
\end{tabular}

In the present tense, the verb stem is inflected with a prefix and a suffix. The prefix gives gender and person information, while the suffix gives number and gender information, as shown in Table 2. 
Table 2. Present verb agreement system

\begin{tabular}{|c|c|c|c|c|c|}
\hline Person & Number & Gender & Affix & Example & Gloss \\
\hline 1 & Singular & $\mathrm{M} / \mathrm{F}$ & Pa- & $? a-\hbar a d^{k} u r u$ & I am attending \\
\hline 2 & Singular & M & ta- & 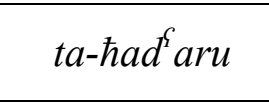 & $\begin{array}{l}\text { You (m.) are } \\
\text { attending }\end{array}$ \\
\hline 2 & Singular & $\mathrm{F}$ & ta--iin & 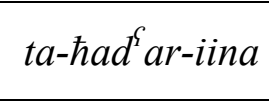 & $\begin{array}{l}\text { You (f.) are } \\
\text { attending }\end{array}$ \\
\hline 3 & Singular & $\mathrm{M}$ & ya- & $y a-\hbar a d^{\natural} u r u$ & $\mathrm{He}$ is attending \\
\hline 3 & Singular & $\mathrm{F}$ & ta- & 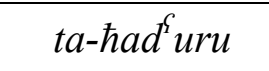 & She is attending \\
\hline
\end{tabular}

The surface morphological marking of gender in Arabic is very complicated and complex. This complexity constitutes a challenge for Arabic L2 learners, and possibly more so when their L1s have a different gender system, or have no gender system at all. Subject-verb agreement was chosen over other gender agreement systems (e.g. nounadjective) because in order to communicate properly L2 learners need to produce verbal sentences, which minimally consist of a verb and a subject, and therefore it is very important to acquire this agreement system. Moreover, as mentioned above there is variation in the affixes depending on the tense and word order, which makes the system more complex.

This study will first present some theoretical background on L1 transfer and UG in second language acquisition. Then in Chapter 3, the concept of grammatical gender will be addressed, followed by previous research on grammatical gender in different languages and previous research of Arabic as a second language. Then the research questions of this study will be introduced, followed by the predictions. Chapter 4 describes the methodology of this study, the participants, the tasks conducted, and the procedures applied. Chapter 5 presents the results of this study, followed by a discussion of the results in Chapter 6. Finally, the study will be concluded with indications for further research. 


\section{Chapter 2: Second Language Acquisition: Language Transfer and Universal Grammar}

There has been a considerable amount of literature published on the influence of first languages on the course of second language acquisition (SLA) (Odlin, 1989, 2003; Gass \& Selinker, 1993). Although this issue has been discussed among linguists, second language researchers and teachers for many years, this topic is still under debate. The concept of language transfer has always been linked to other linguistic and non-linguistic phenomena, including but not limited to typological distance, degree of markedness, processing load, and learners' individual strategies (Hakansson, 2001). In recent decades, with the increased attention on the concept of Universal Grammar (henceforth UG) to SLA, many studies (e.g. White, 1991; 1993; Schwartz \& Sprouse 1994, 1996) have attempted to explore language transfer in light of this framework. Notably, this interest was intensified following Chomsky's (1981a) introduction of the Principles and Parameters approach. The following sections will discuss some aspects of L1 transfer and UG in SLA research.

\subsection{The role of $L 1$ transfer in second language acquisition}

Language transfer is defined as "the influence resulting from similarities and differences between the target language and any other language that has been previously (and perhaps imperfectly) acquired" (Odlin, 1993, p.27). Two types of transfer occur: negative transfer, and positive transfer. Negative transfer is a result of differences between the two languages (i.e. interference), which makes learning L2 more difficult and lengthy. Lado (1975) explains: 
"the student who comes in contact with a foreign language will find some features of it quite easy and others extremely difficult. Those elements that are similar to his native language will be simple for him, and those elements that are different will be difficult" (p.2)

Positive transfer, on the other hand, is a result of the similarities and matches between structures in the two languages, which consequently facilitate the acquisition of L2.

During the past four decades, there has been some disagreement among researchers over the extent to which L1 affects the acquisition of L2 (e.g. Flynn, 1996; White, 1989; Schwartz, 1998; Sabourin, 2003). In this respect, three logical positions regarding transfer are assigned to the role of L1 in L2 acquisition, namely, no transfer, partial transfer, and full transfer. The no transfer position suggests that L1 has no effect on the acquisition of L2. Some advocates of this position claim that the grammatical development of L2 learners in the target language happens through their access to UG, which makes it possible for them to achieve an L2 grammar equivalent to that of the final state grammar of native speakers of the target language (e.g. Platzack, 1996; Epstein, Flynn and Martohardjono, 1996). Others explain L2 learners' success by attributing it to general problem-solving skills (Muysken, 1986; Meisel, 1997). Clahsen and Muysken (1986) conducted research comparing the acquisition of word order between children learning German as their L1 and adults learning German as their L2. They found that children were able to figure out at an early stage that German is an SOV language, whereas adult learners tended to "make use of SVO order irrespective of their language background, even in those cases in which SOV is suggested by the target and the source language" (p.110). This finding led them to conclude that learners' L1 is not involved in their acquisition of a second language. However, this conclusion has been challenged by other L2 studies on the acquisition of SOV languages such as Dutch (e.g. Jansen, 
Lalleman and Muysken 1981; Van der Craats 1994) and German (e.g. Meisel, Clahsen and Pienemann 1981; Vainikka and Young-Scholten 1994, 1996). These studies found that L2 learners who are native speakers of SOV languages like Turkish and Korean tend to start with SOV order in learning Dutch or German as an L2. Moreover, native speakers of SVO languages such as Arabic, Italian, and Spanish start out with SVO when learning Dutch or German. These results show that different L2 learners with different L1s that vary in verb-complement orders use different word orders in the early stages of L2 acquisition. Thus, it is highly accepted that L1 plays a significant role during the course of L2 acquisition (Sabourin, 2003; Sabourin et al., 2006; Franceschina, 2005; WhongBarr, 2006), and there is a general agreement that this is especially so at the initial stage (White, 1985, 1990; Smith and Tsimpli, 1995; Schwartz and Sprouse, 1996; Hulk, 1991; among others). In light of these conclusions, the no transfer position will not be discussed further in the present study.

The second position, partial transfer, indicates that some properties of L1 are transferred into the L2 grammar at least in the initial stages of learning through lexical categories only or lexical and functional categories together. Although partial transfer is a subject of dispute with regard to which parts of L1 are carried over to L2 and which parts are not (Sabourin, 2003), various proposals have emerged supporting this position. For instance, Vainikka and Young-Scholten's (1994, 1996) "Minimal Trees hypothesis" states that only L1 lexical categories can be transferred, while functional categories cannot. Functional categories are assumed to be gradually developed in response to L2 input and UG-constrained structure building. However, this hypothesis has been challenged by other findings that show transfer of functional projections and feature 
specifications, as provided by White's (1991a, 1991b, 1992) studies of adverb placement, where she found that French-speakers learning English as L2 show evidence of verb movement to a functional category. White found that French learners transferred the French adverb orders to English, thus producing Subject Verb Adverb Object (SVAO) sequences, while in English the correct order is Subject Adverb Verb Object (SAVO). This result suggests that the functional category parameters of L1 were adopted in the L2 grammar. Another proposal in favor of partial transfer is suggested by Eubank's (1994, 1996) Valueless Features hypothesis. He claims that the L2 initial state includes both L1 lexical and functional categories as well as functional features. However, he insists that functional features are neither strong nor weak, but instead valueless (or inert). These functional features are said to be acquired during the course of development, and, at the end stage of acquisition, L2 learners are expected to convert to the L2 grammar.

The final and third position, full transfer, predicts that, at least in the initial stages, all aspects from L1 are transferred into the L2 grammar. In other words, the L1 grammar final state constitutes the L2 grammar initial state. Researchers who advocate in favour of this position are in disagreement about the subsequent grammatical development. White (1989) - the first researcher to introduce this position - claims that L2 learners start initially with L1 parameter values and then reset them according to L2 values; that is, she argues that L2 learners have access to UG. Following White (1998), the Full Transfer/ Full Access hypothesis established by Schwartz (1998) and Schwartz and Sprouse (1994, 1996) asserts that L2 learners carry all the grammar structures of their L1 to the L2. ${ }^{7}$ On the other hand, others such as Clahsen and Hong (1995) and Schachter $(1989,1990)$

7 This hypothesis will be discussed later in more detail. 
argue that L2 learners cannot reset parameters that are not instantiated in the L1 grammar, and when the L1 transferred grammar cannot accommodate the L2 input, learners will rely on general problem-solving strategies.

In addition to the degree of transfer, there are two types of transfers presented in the current literature (Sabourin, 2003; Sabourin et at, 2006): surface transfer, which refers to transferring surface features (such as word order and gender marking) from one language to another, and deep transfer, which deals with the transfer of more abstract features of language (such as gender categories) from one language to another.

\subsection{Universal grammar and second language acquisition}

Universal grammar is an innate biological language system of abstract constraints that guides the acquisition of L1 by restricting the class of possible natural human grammars. UG is comprised of invariant principles generally shared by all languages, as well as parameters that allow for variation across languages (White, 1989). There has been extensive debate on whether UG assists learners (particularly adults) through the process of SLA as it does in L1 acquisition (White, 2003), especially in the presence of obvious differences between L1 and L2 acquisition, such as the cognitive status of mature L2 learners, their previous experience in their native language, the method of learning (as they often receive formal instructions and corrections in L2 acquisition), and individual differences in mastering L2 (Bley-Vroman, 1989). Some researchers have argued that UG continues to operate in L2 acquisition, claiming that the differences between L1 and L2 are only quantitative (White, 1989). In contrast, other researchers have maintained that L2 acquisition is qualitatively different from L1 acquisition and, as a result, UG does not govern the process of L2 acquisition (Bley-Vroman, 1989, 1990). However, one of 
the fundamental focuses of the current literature on the subject is whether or not adult L2 learners have access to UG and whether this access, if it exists, is full or partial. If UG is accessible to L2 learners, then they are expected to be more apt at adopting the L2 grammatical categories available in their L1. They are also expected to accommodate the input from L2 that is not available in their L1 by accessing UG. In other words, they can use their access to UG to reconstruct and reprogram their grammatical categories to accommodate any input from L2.

White $(1989,2003)$ states that access to UG principles and parameters in the course of SLA is controversial, making various approaches arise. These approaches vary based on the degree of UG accessibility by adult L2 learners as follows: (1) no access: UG is no longer available to L2 learners; (2) full access: UG is fully available to L2 learners; and (3) partial access: UG is partially available to L2 learners. These approaches interface with the effect of L1 transfer discussed above.

The first approach assumes that UG is no longer available to adult L2 learners, and is therefore not involved at any stage of L2 acquisition. Researchers who argue for this position emphasize the difficulties faced by L2 learners, and the differences between L1 and L2 acquisition. Some proponents of this view, who argue against L1 transfer, claim that L2 acquisition is totally different from L1 acquisition, in which L1 acquisition is directed by UG, while L2 acquisition is guided by means of general problem-solving skills. In this respect, L2 learners' level of proficiency is attributed to successful general learning strategies or other factors, such as cognitive ability and motivation (e.g. BleyVroman, 1989; Clahsen and Muysken, 1986; Clahsen, 1990; Meisel, 1997). In Clahsen and Muysken's (1989) study of word order in German, the authors explain children's 
facility in L2 acquisition compared to adult L2 learners by the fact that adult learners cannot access UG and depend instead on general learning strategies. Other proponents of the no access approach emphasize the role of L1 transfer whether partial (Eubank, Bischof, Huffstutler and West (1997) or full (Clahsen and Hong, 1995).

The second approach is the full access approach. In contrast, it states that UG is fully available to adult L2 learners, meaning that the language faculty involved in L1 acquisition is involved in adult L2 acquisition in the same manner (Flynn, 1996). UG was motivated in the first place because native speakers end up with a highly complex grammar that goes beyond linguistic input. In other words, the input is said to underdetermine the output, which suggests that universal principles guide the acquisition of language (White, 1990). This logical problem of L1 acquisition has encouraged SLA researchers to argue that if L2 learners are also able to adopt highly complex grammar that goes beyond the input, and thus is not reduced to simple general learning strategies or native language information, then UG mediates L2 acquisition as well. It seems most unlikely that L2 input is the only source that builds L2 learners' grammar, and therefore, L2 input will underdetermine the L2 grammar as it happens in L1 acquisition (White 1985a). Hence, it is suggested that the acquisition of L1 and L2 are contingent on UG, and that $\mathrm{UG}$ is the rationale behind the acquisition of complex linguistic knowledge in both situations. Within this view, there are two possibilities: a) L2 learners would draw primarily from UG except under circumstances in which the L1 grammar provides guidance, or b) L2 learners would first begin by mobilizing transferable knowledge gained from their L1, and then resort to UG if this first method is inefficient or insufficient. 
White's (1985) study on the 'pro-drop' (PD) parameter offers evidence for the validity of the full access approach. In her research, she examines L1 Spanish (+PD) and French (-PD) speakers who are learning English (-PD) as an L2. She found that the Spanish speaking group and French speaking group behaved differently, in that the Spanish group tended to change the parameter due to the lack of PD features in their L1, which proved to be challenging. She concludes that there is L1 transfer, and that L2 learners start out with their L1 parameter and then change it according to the target language value.

Furthermore, Schwartz and Sprouse $(1994,1996)$ propose what they call the Full Transfer/ Full Access (FTFA) approach, which states that "the initial state of the L2 acquisition is the final state of L1 acquisition (Full Transfer) and that failure to assign a representation to input data will force subsequent restructurings, drawing from options of UG (Full Access)" (Schwartz and Sprouse, 1996, p. 40). In other words, the L1's entire grammar, including all abstract properties, constitutes the initial state of L2. These authors claim that the grammar that L2 learners start with is gradually going to change. When L1 grammar fails to accommodate the L2 input, the learners call upon unused options of UG, including new parameter settings, functional features, and feature values. Although this hypothesis claims that there exists full access to UG, L2 learners' final outcome grammar might differ from the native grammar of the target language. Regardless, it is still UG constrained since L2 learners start the L2 initial state grammar from their L1 grammar values, leading them to analyze the input differently and to construct grammar values that differ from those of native speakers. Schwartz and Sprouse argue that a learner might come up with parameter settings that are neither part of L1 nor 
L2, but still fall within the range sanctioned by UG.

Many studies (e.g. Haznedar, 1997; Yuan, 1998; Slabakova, 2000) have supported the FTFA hypothesis. Yuan (1998) explored the acquisition of the Chinese long-distance reflexive "ziji" by English and Japanese L2 learners at different levels of proficiency. Yuan's results showed that intermediate groups treat ziji differently. Unlike the Japanese group who did as well as Chinese native speakers, the English group proved to be significantly worse as their L1 did not have a similar property. Such a result offers meaningful support to the full transfer approach. The results also showed that advanced English groups were able to acquire the Chinese reflexive, further supporting the full access approach. Along the same line, Dugarova (2007) examined Russian and English L1 speakers learning Chinese as their L2. This study also tested the Chinese reflexive "ziji". In Russian reflexives, one can only take a local antecedent in finite clauses, but can take a long-distance or local antecedent in non-finite clauses. Dugarova found that Russian learners performed poorly on Chinese long-distance reflexives in finite clauses, suggesting the influence of their L1. For the English groups, the results indicated that the long-distance reflexives in both finite and non-finite clauses were well acquired, even though this structure is not found in their L1. In sum, such findings support the FTFA hypothesis.

Another variation of the full access position is Epstein et al. (1996) and Flynn's (1996) Full Access without Transfer hypothesis. Although these authors agree with Schwartz and Sprouse's Full Access/ Full Transfer hypothesis' proposition that parameter resetting is in principle possible, they are in disagreement about L1 transfer. They assert that $\mathrm{L} 1$ grammar is not transferred onto the L2 at any stage during the acquisition of L2, 
but rather, L2 learners will reset L2 values according to UG's interaction with L2 input.

The final approach to be considered here is the partial access to UG. Advocates of this approach declare that L2 learners are able to partially access UG, although they disagree about which parts are accessible and which are not. On this, there are two stances. The first recognizes L2 learners' access to UG principles but denies the possibility of resetting parameters, while the second assumes that both UG principles and parameters are accessible to L2 learners but that some features of functional categories are not.

The first view is attributed to Tsimpli and Roussou (1991), and Smith and Tsimpli (1995). According to their hypothesis, L1 grammar is the starting point of L2 acquisition. L2 learners can acquire the L2 grammar only via L1 parameter settings, but they cannot reset parameters. It is predicted here that L2 learners might develop a grammar that is not found in their L1 or in the L2 but still does not violate UG principles. They assume that parameters are independent from UG principles. That is, parameters are a sub-module of the UG lexicon, particularly functional categories. Smith and Tsimpli (1995) state, "parameterization is defined in terms of a finite set of alternative values that a functional category can be associated with. Cross-linguistic variation is thus restricted to differences in the parametric values of functional categories" (p.24). These functional categories are subject of maturation, and hence, adult L2 learners cannot observe L2 parameters that are not instantiated in their L1 grammars.

The second stance of partial access is represented in the work of Hawkins and Chan (1997) who followed Tsimpli and Roussou's line of reasoning. Hawkins and Chan propose the Failed Functional Features Hypothesis (FFFH), according to which certain 
features of functional categories - instead of the categories themselves - such as Complementiser, Agreement, and Determiner are inaccessible to L2 adult learners. Hawkins and Chan illustrate their proposal by investigating the acquisition of whmovement in English by L2 speakers of Chinese. They found that Chinese learners were not able to acquire English wh-movement fully due to the absence of the same structure in their mother tongue. Consequently, they conclude that when abstract grammatical features are unrealized in L1, adult learners cannot acquire them in L2. Under this view, L2 learners will first tend to map morphological forms from the L2 onto L1 feature specifications. Then, with more exposure to the L2 input, they will move progressively toward the target language, but as L2 learners with no access to certain fixed functional features, they will establish grammar representations differing from those found in the target language and in their L1 grammar as well. According to Hawkins and Chan, these grammars are constrained by the principles of UG.

Table 3 below presents the different positions regarding transfer and UG access, and relevant references.

Table 3 Summary of transfer and UG access positions

\begin{tabular}{c|c|c|c}
\hline Position & Transfer/Access & Development & Reference \\
\hline No transfer & $\begin{array}{c}\text { No transfer/no } \\
\text { access }\end{array}$ & $\begin{array}{c}\text { No effect of L1, and L2 } \\
\text { learners will rely on general } \\
\text { problem-solving and learning } \\
\text { strategies }\end{array}$ & $\begin{array}{c}\text { Muysken, (1986); } \\
\text { Meisel, (1997) }\end{array}$ \\
\cline { 2 - 4 } & $\begin{array}{c}\text { No transfer/full } \\
\text { access }\end{array}$ & $\begin{array}{c}\text { L2 learners will rely on their } \\
\text { access to UG }\end{array}$ & $\begin{array}{c}\text { Epstein, Flynn and } \\
\text { Martohardjono } \\
\text { (1996) }\end{array}$ \\
\hline
\end{tabular}


Table 3 Cont'd

\begin{tabular}{|c|c|c|c|}
\hline \multirow{2}{*}{$\begin{array}{l}\text { Partial } \\
\text { transfer }\end{array}$} & $\begin{array}{c}\text { Minimal Trees } \\
\text { hypothesis: lexical } \\
\text { categories but not } \\
\text { functional categories } \\
\text { are transferable }\end{array}$ & $\begin{array}{c}\text { Functional categories are } \\
\text { acquired gradually as a result } \\
\text { of L2 input exposure, just as } \\
\text { L1 acquirers are assumed to } \\
\text { do. }\end{array}$ & $\begin{array}{l}\text { Vainikka and } \\
\text { Young-Scholten } \\
(1994,1996)\end{array}$ \\
\hline & $\begin{array}{l}\text { Valueless Features } \\
\text { hypothesis: } \\
\text { Functional features } \\
\text { are valueless }\end{array}$ & $\begin{array}{c}\text { Functional features become } \\
\text { specified for L2 feature values. }\end{array}$ & $\begin{array}{c}\text { Eubank (1994, } \\
1996)\end{array}$ \\
\hline \multirow{4}{*}{$\begin{array}{l}\text { Full } \\
\text { transfer }\end{array}$} & $\begin{array}{l}\text { Full transfer/Full } \\
\text { access } \\
\text { (FTFA) }\end{array}$ & $\begin{array}{l}\text { L2 learners start initially with } \\
\text { L1 parameter values and then } \\
\text { reset them according to L2 } \\
\text { values }\end{array}$ & $\begin{array}{l}\text { White (1989); } \\
\text { Schwartz and } \\
\text { Sprouse (1994) }\end{array}$ \\
\hline & $\begin{array}{l}\text { Full transfer/Partial } \\
\text { access }\end{array}$ & $\begin{array}{l}\text { L2 learners cannot reset } \\
\text { parameters that are not } \\
\text { instantiated in the L1 } \\
\text { grammar; they will rely on } \\
\text { general problem solving } \\
\text { strategies. }\end{array}$ & $\begin{array}{l}\text { Schachter (1989, } \\
\text { 1990); Clahsen and } \\
\text { Hong (1995) }\end{array}$ \\
\hline & $\begin{array}{l}\text { Full transfer/Partial } \\
\text { access: } \\
\text { UG principles are } \\
\text { available but no } \\
\text { possibility for } \\
\text { parameters resetting }\end{array}$ & $\begin{array}{l}\text { L2 learners can acquire the L2 } \\
\text { grammar only via L1 } \\
\text { parameter settings, but they } \\
\text { cannot reset parameters. }\end{array}$ & $\begin{array}{l}\text { Tsimpli and } \\
\text { Roussou (1991), } \\
\text { and Smith and } \\
\text { Tsimpli (1995). }\end{array}$ \\
\hline & $\begin{array}{c}\text { Failed Functional } \\
\text { Feature (FFFH): } \\
\text { UG principles and } \\
\text { parameters are } \\
\text { accessible to L2 } \\
\text { learners but some } \\
\text { features of } \\
\text { functional categories } \\
\text { are not }\end{array}$ & $\begin{array}{l}\text { L2 learners will first tend to } \\
\text { map morphological forms } \\
\text { from the L2 onto L1 feature } \\
\text { specifications. Then, with } \\
\text { more exposure to the L2 input, } \\
\text { they will move progressively } \\
\text { toward the target language. }\end{array}$ & $\begin{array}{c}\text { Hawkins and Chan } \\
\text { (1997) }\end{array}$ \\
\hline
\end{tabular}

The focus of the present study is on two of the above-mentioned positions: the Full Transfer/Full Access (FTFA) hypothesis and the Failed Functional Feature Hypothesis (FFFH). 


\section{Chapter 3: Language Acquisition and Grammatical Gender}

This section will review previous research on the acquisition of gender systems in different languages, followed by previous SLA studies in Arabic.

\subsection{Previous research on grammatical gender}

The acquisition of the grammatical gender system is considered one of the most challenging structures that L2 learners need to acquire/learn. Part of this difficulty lies in the complexity of the system itself, but this system is also one of the significant areas in which languages differ. Research concerning gender acquisition in SLA is large, and researchers have investigated this issue under different theoretical frameworks such as Universal grammar (e.g. White et al, 2004; Hawkins, 1998; Franceschina, 2005), error analysis (e.g. Al-Ani, 1973, Rogers, 1987; Finneman, 1992), and Processability Theory (e.g. Nielsen, 1997; Alhawary, 2003). With respect to research that treats this issue in the context of the access/transfer theories, a number of studies have examined the effect of L1 transfer on acquiring L2 grammatical gender by adult learners, but fewer studies have explicitly considered UG access in relation to this topic.

Sabourin (2001) investigated the effects of L1 on off-line processing of Dutch grammatical gender by adult L2 learners. The learners were native speakers of German, a Romance language (either French, Italian, or Spanish), and English. German has a similar grammatical gender system to Dutch. Romance languages have a gender system but it differs from the one employed in Dutch. English has no grammatical gender system. There were also native speakers of Dutch participating as a control group. With regard to gender agreement, Sabourin's findings showed a hierarchy of performances with 
significant differences between learners. The German group achieved the better score among the L2 learner groups, but still placed significantly lower than the native speakers. The Romance group not only performed significantly worse than the native speakers, but also worse than the German group. The English group had the worst results. Sabourin concluded that the presence of a grammatical gender system in L1, as well as the similarity between this system in L1 and L2, strongly influence the acquisition of the L2 grammatical gender system.

In another study, Sabourin et al. (2006) examined the role of transfer from different L1s in learning the Dutch grammatical gender system. Adult L2 learners of Dutch whose L1 was either German, English, or a Romance language were investigated. Participants were tested on both gender assignment and agreement. Sabourin et al. found that all learners were able to assign the correct gender to nouns. The results showed that transfer from L1 was not necessary for learners to acquire gender assignment since the English speakers, who have no gender system in their L1, were able to accomplish this task. This being said, transfer from L1 did prove to be important in facilitating the acquisition of gender agreement, as the German and Romance groups scored much better than the English group, with the German group in the lead.

In a recent study, Ellis et al. (2012) also examined the acquisition of grammatical gender in German by L2 adult learners. Participants' L1s were either Afrikaans, English, or Italian. Italian is a language that has a gender system but it differs from that of German, whereas Afrikaans and English lack gender systems. The findings indicated that the Italian group outperformed the Afrikaans and English groups, which provides evidence in favor of an L1 effect. Ellis et al. further concluded that their results support 
the deep transfer position (transferring abstract grammatical categories) since the grammatical gender systems in Italian and German are not congruent.

Franceschina (2002) investigated the acquisition of case, number, and gender agreement in Spanish by learners who were native speakers of English, French, German, Greek, Italian, and Portuguese. The participants were grouped based on the presence or absence of gender systems in their L1s. One group of participants included speakers of French, German, Greek, Italian, and Portuguese based on the presence of a gender distinction system in these languages. The other group included only native speakers of English, based on the absence of a gender system in this language. Also, native speakers of Spanish served as a control group. Results showed significant differences between the three groups. All groups performed well with regard to number and structural case; however, there was a significant difference in performance when it came to gender. The "no gender" group performed significantly worse than the other two groups, whereas the difference between the L1 Spanish group and the "+Gender" group was insignificant. The author concluded that her findings tend to support the FFFH, which states that L2 learners are incapable of acquiring abstract grammatical features that are not found in their L1.

In contrast to the results of the above study, White et al. (2004) investigated how L2 learners who vary in their L1s acquire Spanish gender and number agreement. The participants were native speakers of French (a language with a gender distinction system), and English (a language with no gender system). All of them were adult learners. Spanish was the L2 for some of them, and the L3 for others. Twenty native speakers of Spanish participated as a control group. Based on a Spanish proficiency test, 
participants were divided into three levels of proficiency: low, intermediate, and advanced. The study included different tasks to test the learners' production and comprehension of the Spanish gender system. Results from the production and comprehension tasks were highly consistent. White et al. found that number agreement was acquirable by all learners. In both tasks, participants with lower proficiency showed more accuracy on number agreement than on gender agreement, and on masculine nouns more than feminine ones. The advanced and intermediate groups performed about as accurately as native speakers. Moreover, the findings indicated that there were significant effects of proficiency but not of L1 or of prior exposure to an L2 with a gender system. Learners whose L1 was English were able to perform well in both tasks (production and comprehension), just like the French L1 and native speaker control groups. White et al. declared that their findings are in contrast with the FFFH, but support the FTFA to some extent. They admitted that although the findings strongly support the full access position, they cannot do so for the full transfer position, as the FTFA hypothesis predicts L1 effects at the low proficiency level, at least at the initial stages, and these effects were absent in their results.

Bond et al. (2011) conducted an event-related potential (ERP) study to examine number and gender agreement in Spanish by native speakers of English. Number features on verbs are similar between the two languages, but number features on adjectives, and gender agreement are only present in Spanish. The findings indicated that the participants were able to develop native-like processing in terms of gender agreement, even though it is a feature that is not instantiated in their L1. Again, their conclusion supports the FTFA. 


\subsection{Previous studies in Arabic}

During the past decades, there have been a number of studies conducted on Arabic as a second language, although it is still marginal compared to SLA research on other languages such as English and French. A number of earlier studies in the field of SLA have investigated the acquisition of Arabic under the theory of Contrastive Analysis and Error Analysis (e.g. Alani, 1972, 1973; Rammuny, 1976), and Developmental Analysis (e.g. Albuainain, 1986, 1991). These studies have attempted to identify either L2 learners' errors with certain grammatical structures, or the developmental stages of acquiring a given set of grammar rules. Other studies (Nielsen, 1997; Alhawary, 2003; Mansouri, 2000; Abu Radwan, 2002) have also explored the speech processing of some Arabic morphological and syntactic structures from a developmental perspective by examining Pienemann's $(1992,1998)$ Processability Theory (PT). PT states that learners restructure their L2 knowledge according to processing procedures, which occur in different stages in hierarchical order. In other words, the already processed structures that learners "developed at one stage are necessary prerequisites for the following stage" (Pienemann, 1998, p. 87). According to PT, learners can only produce what they have processed. Studies within the PT framework have yielded unexpected findings regarding the order in which L2 learners of Arabic acquire certain grammatical features such as definite articles or nouns, noun-adjective (N-A) agreement, and subject-verb (S-V) agreement. For example, while PT suggests that N-A agreement emerges in learners' interlanguage before S-V agreement, Nielsen (1997) found that both structures emerged at the same time in one participant's interlanguage, and none of these structures were present in another participant's. Likewise, Alhawary $(1999,2003)$ found that the majority of his participants acquired S-V agreement before N-A agreement, though 
participants received formal instruction on $\mathrm{N}-\mathrm{A}$ agreement before they did on $\mathrm{S}-\mathrm{V}$ agreement.

Mansouri (1995) investigated the acquisition of Arabic subject-verb agreement from a discourse-based perspective. He tested the effect of word order, semantic information (humanness-animacy and collectivity), and discourse cues (naturalness of the subject, discourse coherence, lexical cues) on the acquisition of subject-verb agreement morphology in Arabic. The subjects were five native speakers of English learning Arabic in an Australian university. The participants were all at a high level of proficiency. Two written tasks were used in which learners were asked to fill in a blank in front of a verb with the appropriate person, number, and gender markers. Mansouri found that all these factors (person, gender, and number) were significant in terms of helping the learners to identify the correct form of verbs. He concluded that these factors are important in predicting and assessing the L2 learners' final outcome with regard to subject-verb agreement.

Within the framework of UG and L1 transfer theories, Bolotin (1996a) conducted a study to determine whether L2 learners of Arabic have access to UG principles and parameters. The main focus of the study was to test if learners can reset the parameters of the Arabic relative clause. Participants were 27 native speakers of English (one student spoke Polish, and two students spoke German as their mother tongue) divided into three groups based on their level of proficiency: beginner $(n=10)$, intermediate $(n=11)$, and advanced $(n=6)$. The study also included six native speakers of Arabic serving as a control group. A grammaticality judgment task was used to elicit data from the participants. The task consisted of simple and complex sentences that were grammatically 
correct in Arabic but not in English, and vice versa. The results showed that the beginning and intermediate groups performed significantly worse than the control group. On the other hand, the advanced group performed as accurately as the control group. Bolotin claimed that these findings indicate that L2 learners of Arabic can ultimately reset Arabic parameters, and that L1 plays an important role at the initial stages.

In the same vein, Alhawary (2005) tested three proposals within the context of UG and L1 transfer, namely, the Local Impairment Hypothesis (Beck, 1998), the FFFH (Hawkins \& Chan, 1997), and the Missing Surface Inflection Hypothesis (Lardiere, 2000). He investigated the acquisition of Arabic morphosyntactic structures including subject-verb agreement, noun-adjective agreement, and noun-adjective word order. The subjects were native English speakers $(\mathrm{n}=27)$ and native French speakers $(\mathrm{n}=26)$ divided into three groups based on the amount of formal instruction in Arabic they had received: first year, second year, and third year. Unlike French, English does not have a grammatical gender system. Data included semi-spontaneous production data on three picture tasks: picture description, picture differences, and picture sequencing. The results indicated that with subject-verb agreement there was no significant difference between the L1 French groups and the L1 English groups. However, there was a significant difference between them with noun-adjective agreement. This was also the case with the L1 English groups in terms of gender categories; that is, English participants faced more difficulty with formal gender than natural gender. The results also revealed that, overall, the L1 French speakers outperformed the L1 English speakers; however, some advanced L1 English participants obtained a perfect score. Alhawary concluded that these results did not support either the Local Impairment Hypothesis (Beck, 1998), or the FFFH 
(Hawkins \& Chan, 1997), but they were partially in line with the Missing Surface Inflection Hypothesis. He further declared that the FTFA hypothesis generally aligns with the results of his study.

In a later study, based on longitudinal and cross-sectional studies, Alhawary (2009) investigated the acquisition of gender agreement in Arabic, including nominal gender agreement and verbal gender agreement. In his longitudinal research, eight native speakers of English and one native speaker of French were observed for the length of a school year. The cross-sectional study included 82 L2 learners of Arabic with different L1s, namely, English, French, and Japanese. Results from both studies showed that participants tended to use masculine gender more than feminine gender in the case of nominal gender agreement. In addition, English L1 and Japanese L1 participants performed significantly worse than French L1 speakers when adding the correct feminine gender marker to adjectives in order to agree with the corresponding feminine nouns. These studies also revealed that, unlike the French L1 participants, both English and Japanese speakers seemed to have more difficulty with nominal agreement than verbal agreement, as their performance on verbal agreement was relatively comparable to that of the French L1 speakers. Moreover, there was no significant difference between all three groups with respect to verbal agreement. Alhawary concluded that these results provide evidence in favor of the FTFA hypothesis.

According to the literature, few studies have investigated the acquisition of grammatical gender agreement in Arabic L2 learners, specifically in relation to the UG and transfer hypotheses. The current study is an attempt to fill the existing gap in the field of Arabic SLA. 


\subsection{The current study}

According to the literature reviewed above, the FTFA and FFFH make different predictions regarding the acquisition of L2 grammatical gender by adult L2 learners. First, the FTFA claims that L2 learners can acquire the L2 gender agreement whether their L1 has a gender agreement system or not. The FFFH, on the other hand, claims that only L2 learners whose L1s have a gender agreement system can master the gender agreement system in the L2. Second, the two hypotheses agree upon the significant effect of L1 transfer, at least in the initial stages of language acquisition; however, they differ with respect to the following developmental stages of acquisition. The FTFA suggests that, at the earlier stages, L2 learners with different L1s should represent different knowledge of L2 grammatical gender, and those L2 learners with grammatical gender systems in their L1 will likely be better than those without a grammatical gender system in their L1. However, L2 learners with no gender system will be able to overcome this difficulty and will eventually achieve knowledge of the L2 gender system similar to those of L2 learners with a gender system in their L1. In contrast, the FFFH predicts that the L1 will determine the acquisition of the L2 gender system, and thus show significant differences at all stages of development. Accordingly, L2 learners with gender systems in their L1s will always outperform learners with no gender system, even at the final stage of acquisition.

The current study sets out to investigate these areas of differences between the FTFA and FFFH by examining the acquisition of the grammatical gender system in Arabic by adult L2 learners. Specifically, it investigates the acquisition of subject-verb gender agreement by two groups of L2 Arabic learners with different L1s. The first group 
(+Gender group) includes learners with L1s that have a verb-subject gender agreement system. The second group (-Gender group) contains learners with L1s that have no verbsubject gender agreement system. This study attempts to answer the following research questions:

1. Can L2 learners acquire Arabic verb-subject gender agreement as accurately as native speakers of Arabic?

2. Among the $\mathrm{L} 2$ learners, can the -Gender groups acquire Arabic verb-subject gender agreement as accurately as the +Gender groups?

3. Will level of proficiency affect the acquisition of gender?

4. Will the results support the FTFA or FFFH hypotheses?

5. Will there be a difference in performance on comprehension and production tasks?

The FTFA and FFFH make the following predictions for questions $1-3$ :

1. a) The FTFA predicts that both advanced L2 learner groups (the +Gender group and the -Gender group) will acquire Arabic verb-subject gender agreement as accurately as the native speakers control group.

b) The FFFH predicts that only the advanced +Gender group will acquire Arabic verbsubject gender agreement as accurately as the native speakers control group.

2. a) The FTFA predicts that the advanced -Gender group will acquire Arabic verbsubject gender agreement as accurately as the advanced + Gender group. 
b) The FFFH predicts that the advanced + Gender group will outperform the advanced -Gender group.

3. a) The FTFA predicts that the intermediate + Gender group might outperform the intermediate -Gender group.

b) The FFFH predicts that the intermediate + Gender group will outperform the intermediate -Gender group.

4. a) The FTFA predicts that both advanced +Gender and -Gender groups will outperform both intermediate learner groups.

b) The FFFA does not make predictions about different stages of acquisition, as it is always concerned with the end state. 


\section{Chapter 4: Methodology}

This chapter discusses the methods that were used to test the research questions, and the different predictions that FFFH and FTFA make. It describes the participants, proficiency test, experimental tasks, and general procedures for the study.

\subsection{Participants}

This study involved two experimental groups and a control group. The L2 learners of Arabic were divided into two groups. The -Gender group consisted of learners whose $\mathrm{L} 1$ does not have a verb-subject gender agreement system, and the +Gender group consisted of learners whose L1 has this feature. Seventy-three Arabic learners were given an Arabic reading proficiency test (see section 5.2.1), and according to the results of this test they were divided into three proficiency levels: beginner (less than 50\%), intermediate $(50-85 \%)$ and advanced $(85-100 \%)$. The beginner participants $(\mathrm{n}=9)$ were eventually eliminated from the study because their scores on the experimental tasks were too low to provide meaningful data. For example, one beginner participant had mean scores of $0.54,0.45$, and $0.87 \%$ on the written experimental tasks. In addition, twentyone participants were removed from the study for various other reasons. Nine participants were removed because they were bilingual from childhood in one language with a grammatical gender system and one without. For example, two native speakers of Pashto (+Gender) were also speakers of Urdu (-Gender). Likewise, two participants who were native speakers of Uzbek and Tajik (both -Gender) were bilingual in Russian (+Gender). Six participants were removed because they had been exposed to the Arabic language at a young age; two of them had lived in Arabic-speaking countries, and four had taken 
Arabic classes in primary school in their home countries. Five other participants were eliminated because they did not continue after the first task. Finally, four participants were removed because they had left more than $50 \%$ of sentences without corrections in the grammaticality judgment task, more than $70 \%$ of sentences blank in the sentence completion task, and did not show up for the Picture Description Task. Of the original 73 Arabic learners, 40 were kept for the analysis, including 26 participants in the - Gender group and 14 participants in the + Gender group. Table 4 provides information on these 40 participants.

Table 4. Participant information

\begin{tabular}{|c|c|c|c|c|}
\hline Group & $\begin{array}{c}\text { Level of } \\
\text { Proficiency }\end{array}$ & L1 language family & L1 & No. of speakers \\
\hline \multirow{7}{*}{-Gender } & \multirow{3}{*}{$\begin{array}{c}\text { Intermediate } \\
\text { level } \\
(\mathrm{n}=12)\end{array}$} & Malayo- polynesian & $\begin{array}{l}\text { Indonesian } \\
\text { Tagalog } \\
\text { Malay } \\
\text { Maguindanaon }\end{array}$ & $\begin{array}{l}1 \\
2 \\
4 \\
3\end{array}$ \\
\hline & & Sino- Tibetan/ Chinese & Dungan & 1 \\
\hline & & Turkic & Kyrgyz & 1 \\
\hline & \multirow{4}{*}{$\begin{array}{c}\text { Advanced } \\
\text { level } \\
(n=14)\end{array}$} & Malayo- polynesian & $\begin{array}{c}\text { Indonesian } \\
\text { Tagalog } \\
\text { Malay } \\
\text { Maguindanaon } \\
\end{array}$ & $\begin{array}{l}4 \\
1 \\
1 \\
1 \\
\end{array}$ \\
\hline & & Sino- Tibetan/ Chinese & Chinese & 4 \\
\hline & & Turkic & Uzbek & 3 \\
\hline & & & & Total $=26$ \\
\hline \multirow{4}{*}{+ Gender } & $\begin{array}{c}\text { Intermediate } \\
\text { level } \\
(n=6)\end{array}$ & Indo- Iranian/ Indo- Aryan & $\begin{array}{l}\text { Nepali } \\
\text { Urdu }\end{array}$ & $\begin{array}{l}1 \\
5\end{array}$ \\
\hline & \multirow{3}{*}{$\begin{array}{c}\text { Advanced } \\
\text { level } \\
(\mathrm{n}=8)\end{array}$} & Indo- Iranian/ Indo- Aryan & $\begin{array}{l}\text { Nepali } \\
\text { Urdu }\end{array}$ & $\begin{array}{l}1 \\
5\end{array}$ \\
\hline & & Romance & French & 2 \\
\hline & & & & Total $=14$ \\
\hline
\end{tabular}


The participants were recruited at the Arabic Linguistics Institute at King Saud University in Riyadh, Saudi Arabia. All of them were studying Arabic for academic purposes. All learners were adults and their age at the time of testing ranged from 21 to 32 (mean age of 23.5 years). All participants were first exposed to Arabic after puberty.

In addition, fifteen adult native Arabic speakers participated in the experiment as the control group. All of them were graduate or undergraduate students at King Saud University, and they were between 21 and 32 years of age (mean age 25.7 years). They were recruited through a departmental announcement. For all of them, Arabic was their mother tongue and the language of their primary education. Some of them spoke English as a second language. All participants in this study were male.

\subsection{Language tasks}

\subsubsection{Proficiency Test}

A reading proficiency test was given to the participants to determine their proficiency level in Arabic for this study. The test is part of a standardized Arabic proficiency test administrated by the Arabic Linguistics Institute at King Saud University. The test consisted of 40 multiple-choice questions divided into three parts: the first part included questions about different pictures, the second part asked participants to read short passages and then answer questions by choosing the correct answer, and the third part asked participants to read long passages and then answer questions by choosing the best answer.

\subsubsection{Grammaticality Judgment Task (GJT)}

A written Grammaticality Judgment Task was administrated to test participants' 
comprehension of subject-verb gender agreement in Arabic. Participants were presented with 122 sentences consisting of 56 experimental sentences and 56 fillers. Half of the 56 experimental sentences were grammatical, and the other half were ungrammatical. The grammatical sentences were divided into four categories: 7 sentences in the past tense with masculine verbs and masculine subjects, 7 sentences in the past tense with feminine verbs and feminine subjects, 7 sentences in the present tense with masculine verbs and masculine subjects, and 7 sentences in the present tense with feminine verbs and feminine subjects. The following examples are sentences used in the Grammaticality Judgment Task that show the four categories mentioned above:

(5) a. Masculine verb, Masculine subject, Past

$$
\begin{aligned}
& \text { اثتترى محمدُ قلمًا جديدًا } \\
& \text { Pštaraa moћammad-un qalam-an dzadīd-an } \\
& \text { buy.past.3.s.m Mohammad.s.m pin.s.m new.s.m }
\end{aligned}
$$

'Mohammad bought a new pin'

b. Feminine verb, Feminine subject, Past

كرمت المديرةُ الطالبات المتفوقات

karram-at l-mudīra-tu Pal-ţalib-ati Pal-mutafawwiq-ati

lionize.past-3.s.f the-principal-s.f the-student-p.f the-outstanding-p.f

'The principal lionized the outstanding students 
c. Masculine verb, Masculine subject, Present

يذهبُ الولأُ إلى الطبيبِ كلَّ شهر

ya-ðhabu Pal-waladu Pilaa Pal-t'abībi kulla šahr-in

3.s.m-go.present the-boy.s.m to the-doctor.s.m every month.s.m

'The boy goes to the doctor every month'

d. Feminine verb, Feminine subject, Present

تحبُّ هندُ قراءةً الثُعر

tu-hibbu hindu qira?ata Pal-ši?ri

3.s.f-like.present Hind.s.f reading the-poetry

'Hind likes reading poetry'

The ungrammatical sentences were designed to exhibit disagreement in grammatical gender between the verb and the subject in both past and present tenses. The ungrammatical sentences included 7 sentences in the past tense with masculine verbs and feminine subjects, 7 sentences in the past tense with feminine verbs and masculine subjects, 7 sentences in the present tense with masculine verbs and feminine subjects, and 7 sentences in the present tense with feminine verbs and masculine subjects. Examples of these sentences can be seen below.

(6) a. Masculine verb, Feminine subject, Past

* ركبَ المسافرةُ القطار

rakiba Pal-musafira-tu Pal-qitara 
ride.past.3.s.m the-passenger-s.f the-train.s.m

'The passenger rode the train'

b. Feminine verb, Masculine subject, Past

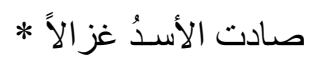

s'ad-at Pal-asadu yazal-an

hunt.past-3.s.f the- lion.s.m deer.s.m

'The lion hunted a deer'

c. Masculine verb, Feminine subject, Present

* بَحكُُ القاضيةُ بينَ المتخاصمينَ

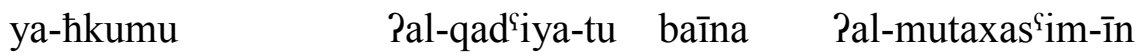

3.s.m-decide.present the-judge-s.f between the-adversary-p.m

'The judge decides between adversaries'

d. Feminine verb, Masculine subject, Present

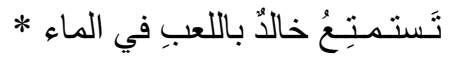

ta-stamti?u xalidun bi-Pal-la?ibi fì Pal-ma?i

3.s.f-enjoy.present Khalid.s.m with-the-playing in the-water

'Khalid enjoys playing in the water'

The 56 fillers were designed to draw the participants' attention away from the structure being investigated. Half of these fillers were grammatical, and the other half were not. Since the incorrect part of the ungrammatical experimental sentences was always at the beginning of the sentences, the ungrammatical fillers were designed to show the incorrect part in the middle or at the end of the sentences. See Appendix A for 
the sentences that were used in the Grammaticality Judgment Task.

The 112 sentences in the Grammaticality Judgment Task were presented to all participants in the same random order. To ensure that learners knew all of the vocabulary items used in the task, the vocabulary was kept very basic, and learners were instructed to ask any questions they had before or during the task.

Participants were asked to judge the sentences in the Grammaticality Judgment Task in one of three ways: (1) grammatically correct, (2) grammatically incorrect, or (3) I do not know. They were also asked to circle or underline the incorrect part of all sentences they marked as ungrammatical.

\subsubsection{Sentence Completion Tasks 1 and 2 (SCT1 and SCT2)}

A written Sentence Completion Task was administrated to examine the production of verb-subject gender agreement. This task consisted of two parts: the first part contained sentences without verbs, and the second part contained sentences lacking nouns. Each part consisted of 32 sentences. Like the Grammaticality Judgment Task, all vocabulary items were high frequency items, and the structure of the sentences was kept basic.

In the Sentence Completion Task 1, participants were asked to fill in the blanks with appropriate verbs in the tense indicated under each blank. The sentences were divided into four categories: (a) 8 sentences involved masculine subjects and missing verbs that should be masculine in the past tense; (b) 8 sentences involved feminine subjects and missing verbs that should be feminine in the past tense; (c) 8 sentences involved masculine subjects and missing verbs that should be masculine in the present 
tense; and (d) 8 sentences involved feminine subjects and missing verbs that should be feminine in the present tense. See Appendix B for a full list of sentences. These sentences were randomly distributed across the test. All sentences in this part were in a V S word order. The following are examples from the four categories:

(7) a. Masculine verb, Masculine subject, Past

$$
\begin{aligned}
& \text { الرجل إلى السوق البارحة } \\
& \frac{}{\text { (Past tense) }} \text { Pal-radzulu Pilaa Pal-ssuqi Pal-bariћata } \\
& \text { the-man.s.m to the-mall last night }
\end{aligned}
$$

'the man to the mall last night'

b. Feminine verb, Feminine subject, Past

$$
\begin{aligned}
& \text {--- }
\end{aligned}
$$

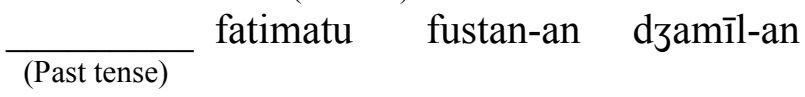

$$
\begin{aligned}
& \text { Fatimah.sf dress nice }
\end{aligned}
$$

'Fatimah a nice dress'

c. Masculine verb, Masculine subject, Present

$$
\begin{aligned}
& \text { ا } \\
& \frac{}{\text { (Present tense) }} \text { xalidu } \min \text { Pal-nnūmi mubakkir-an } \\
& \text { Khalid.s.m to sleep early }
\end{aligned}
$$


d. Feminine verb, Feminine subject, Present

\begin{tabular}{|c|c|c|c|}
\hline \multicolumn{2}{|c|}{ 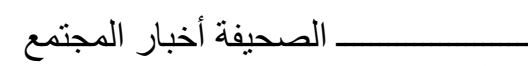 } & \multirow{3}{*}{ axbara } & \multirow{3}{*}{ Pal-mudztam } \\
\hline & (فعل مضارع) & & \\
\hline \multirow[t]{2}{*}{ (Present tense) } & & & \\
\hline & the-magazine.s.f & news & the-society \\
\hline
\end{tabular}

In sentence (7b), for example, the participants were expected to write a verb like "labis$a t$ " (wear.past-3.s.f) to create a meaningful sentence; however, any feminine verb was counted as a correct answer regardless of its meaning. Moreover, even though the tense was specified under each blank, incorrect tense was accepted as long as the verb agreed with the subject in gender. The aim of the Sentence Completion Task 1 was to see whether the participants would be able to inflect verbs with the gender markers in different tenses in order to correctly agree with the subjects.

In the Sentence Completion Task 2, participants were asked to fill in the blank with a suitable noun (see Appendix C). Like the first part, this section also contained four categories: (a) 8 sentences involved masculine verbs in the past tense and missing masculine nouns; (b) 8 sentences involved feminine verbs in the past tense and missing feminine nouns; (c) 8 sentences involved masculine verbs in the present tense and missing masculine nouns; and (d) 8 sentences involved feminine verbs in the present tense and missing feminine nouns. These sentences were randomly distributed across the test. Unlike the first part, all sentences in this section were in an SV word order. The reason for making the sentences SV was to control the number feature, as in Arabic V S word order there is no agreement between the verb and the subject so it is possible to use 
a plural subject after a singular verb. As mentioned before, the present study focuses on subject-verb agreement within the context of the third-person singular. The following examples show the four above-mentioned categories:

(8) a. Masculine subject, Masculine verb, Past

\begin{tabular}{|c|c|c|c|}
\hline حضر في الوقت المحدد & & & \\
\hline had' ${ }^{\complement}$ ara & fì & Pal-waqti & Pal-muћaddadi \\
\hline come.past.3.s.m & on & the-time & the-good \\
\hline
\end{tabular}

b. Feminine subject, Feminine verb, Past

انتـهـت من أداء و اجباتها

Pintah-at min Pdaa?i wadzkbi-haa

finish.past-3.s.f from doing homework-her

‘___ finished doing her homework'

c. Masculine subject, Masculine verb, Present

يمارس الرياضة بانتظام

yu-marisu $\quad$ Pal-ryad ${ }^{\complement}$ ata bi-intið $^{\complement}$ am-in

3.s.m-exercise.present the-sport on- a regular basis exercises on a regular basis' 
d. Feminine subject, Feminine verb, Present

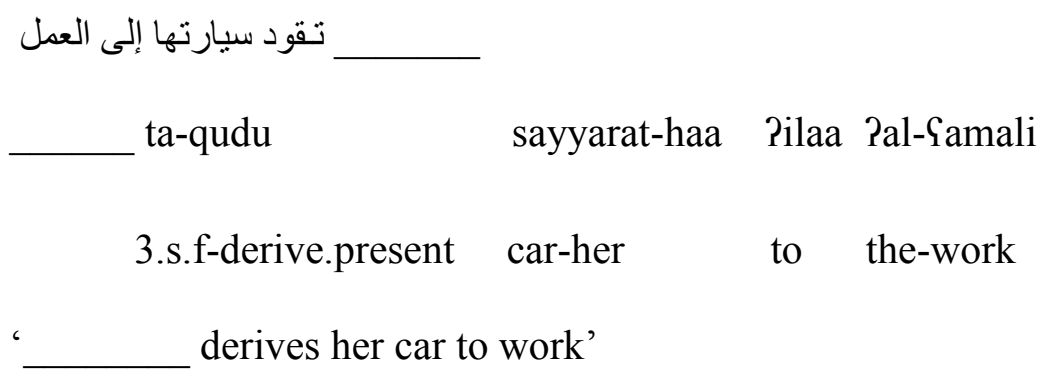

The participants were asked to put an appropriate noun in each blank; however, pronouns were accepted as long as they indicated the correct gender. So, in sentence (8a), for instance, it was predicted that participants would use a noun like "Pal-waladu" (the boy) or "Pћmad" (Ahmad), but they were not penalized if they instead used a pronoun like "huwa" (he).

\subsubsection{Picture Description Task (PDT)}

The Picture Description Task was designed to examine the participants' oral production of Arabic subject-verb gender agreement. In order to elicit sentences that contain verbs and subjects, action pictures were shown to participants. The action pictures showed a person doing a certain activity such as running, swimming, or laughing. These pictures were chosen carefully in order to make them easy for participants to describe, not only in terms of understanding the pictures themselves but also in terms of the vocabulary to be used.

The Picture Description Task consisted of four pictures containing approximately 42 males and females doing different actions (see Appendix D). The participants were shown these pictures on a computer screen, and they were asked to look at them and describe what each individual was doing. The participants were expected to produce 
subjects and verbs in the present tense; for example, a sentence like "Pal-bintu ta-

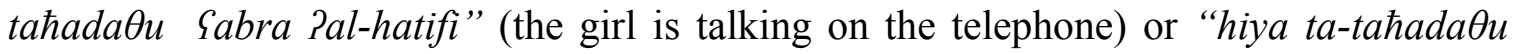
Sabra Pal-hatifi" (she is talking on the telephone). However, it was accepted if a

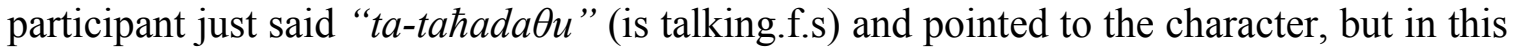
case the researcher asked the participant to determine whether the character was male or female to make sure that he identified the gender correctly. The participants were not restricted to describing people's actions in the pictures, but were rather free to talk about any object or scene. This was important as it served as fillers or distractors. This being said, only the participants' descriptions of people were used in the analysis.

\subsection{Procedures}

Before the researcher traveled to Riyadh, Saudi Arabia to collect data, a pilot study was conducted to uncover any potential problems that might occur using the proposed methods. The pilot study included 15 adult participants, some of whom were native Arabic speakers, and some of whom who had Arabic as their L2. The pilot study results brought much insight to the researcher regarding the preferable methods for administrating the tests, and also showed that some changes needed to be made in terms of content.

The data for this study was collected at King Saud University in Riyadh, Saudi Arabia over two weeks. On the first day, the researcher met with the L2 participants and explained the purpose and procedures of the study. Participants were asked to complete a consent form, followed by a short background questionnaire that asked for biographical data such as age, L1, length of residency in Saudi Arabia, the age at which they began 
learning Arabic, their points of weakness and strength in Arabic, and information about other languages in their background (see Appendix E). Then, they were asked to complete the reading proficiency test. These procedures took approximately 2.5 hours.

On the second day each participant received a package consisting of the Grammaticality Judgment Task and the Sentence Completion Tasks, with a participant ID code printed on each test. The first page of each task contained instructions on how to perform the tests and provided participants with examples. Participants were asked to perform the Grammaticality Judgment Task first, followed by the first and second parts of the Sentence Completion Task. Participants were asked not to look at the other tasks until they had completed the first one and received the permission of the researcher to continue. There was no time limit for participants to do each test; however, participants completed the tasks approximately at the same time (with no more than 15 minutes passing between the first and last participant to finish each task). Participants were allowed to ask about any difficult vocabulary while performing the tests.

The Picture Description Task involved different procedures due to the nature of the task, which requires the researcher to test each participant individually. Participants were asked to come to the researcher's desk in a computer lab at any time during the following two days. Seven participants did not show up for this task. Each participant was asked three questions before starting the test in order to break the ice and make him more comfortable. The three questions were about their experience learning Arabic, their favorite teacher, and their life experience in Saudi Arabia. These questions were not part of the data analysis. After discussing these questions, each participant was asked to look at a computer screen and describe each picture. The participants' answers were recorded. 
Participants were free to ask questions while performing the test. The same procedures were applied with the Arabic native control group in the second week. 


\section{Chapter 5: Results}

\subsection{Proficiency Test}

As discussed in section 5.2.1, the reading proficiency test given to the participants consisted of 40 questions, with each correct question receiving one point. The results for each participant are provided in Appendix F. Table 5 shows the mean score of the Arabic learners and of the native control group. ${ }^{8}$

Table 5: Performance of Arabic learners and native speakers on the Proficiency Test

\begin{tabular}{ccc}
\hline Participant group & Mean & SD \\
\hline Arabic learners & $\mathbf{7 7 . 9 4}$ & 12.71 \\
\hline Native Speakers & $\mathbf{9 8 . 0 0}$ & 2.35 \\
\hline
\end{tabular}

As shown in Table 5, the native control group performed almost perfectly, with a mean of $98.00 \%$, while the mean score of the Arabic learners was $77.94 \%$. An independentsamples t-test revealed that this difference in scores is significant $(t(45.40)=-9.6, p<$ $.001)$.

Table 6 shows the results of the Arabic learners by L1 gender type and proficiency level.

Table 6: Performance of the Arabic learners on the Proficiency Test by L1 gender type and proficiency

\begin{tabular}{cccc}
\hline Proficiency level & $\begin{array}{c}\text { Gender } \\
M(S D)\end{array}$ & $\begin{array}{c}+ \text { Gender } \\
M(S D)\end{array}$ & $\begin{array}{c}\text { Total } \\
\text { Advanced }\end{array}$ \\
\hline Intermediate & $66.79(3.72)$ & $90.31(6.69)$ & $\mathbf{8 8 . 0 7}(5.23)$ \\
\hline Total & $64.792(6.69)$ & $67.08(6.21)$ & $\mathbf{6 5 . 5 5}(6.45)$ \\
\hline & $76.64(12.33)$ & $80.35(13.51)$ & $77.94(12.71)$ \\
\hline
\end{tabular}

\footnotetext{
${ }^{8}$ In the tables in this section, all significant differences are presented in bold.
} 
A two-way ANOVA was conducted with the two independent variables being L1 gender type and proficiency level. Results showed no significant effect of L1 gender type $(F(1,36)=2.28, p=.140)$, but a significant effect of proficiency level $(F(1,36)=$ $137.81, p<.001)$. That is, the advanced learners $(M=88.07)$ performed better than the intermediate learners $(M=65.55)$ on the proficiency test, but overall the -Gender and +Gender groups performed similarly. However, advanced learners still did not perform as well as the native control group (one-way ANOVA: $F(1,35)=47.25, p<.001$ ). There was no significant interaction between L1 gender type and proficiency level $(F(1,36)=$ $.10, p=750)$.

\subsection{Experimental Tasks}

The experimental tests were the Grammaticality Judgment Task, the Sentence Completion Tasks 1 and 2, and the oral Picture Description Task. A full listing of these test results is given in Appendix G-J.

\subsubsection{Grammaticality Judgment Task (GJT)}

The Grammaticality Judgment Task consisted of 28 grammatical sentences and 28 ungrammatical sentences. The grammatical sentences included 14 pairs of masculine verbs and masculine nouns, and 14 pairs of feminine verbs and feminine nouns. The ungrammatical sentences consisted of 14 pairs of masculine verb and feminine noun mismatched, and 14 pairs of feminine verb and masculine noun mismatched. Participants were asked to correctly identify these sentences, and also highlight the incorrect part in each ungrammatical sentence. A score of 1 was given for a correct response, and 0 for an incorrect or "I do not know" response. A perfect mean score is therefore 1. 
Table 7 shows the mean scores of the Arabic learners and the native control group.

Table 7: Performance of the Arabic learners and native speakers on the Grammaticality Judgment Task

\begin{tabular}{ccc}
\hline Participant group & Mean & SD \\
\hline Arabic learners & $\mathbf{0 . 8 2}$ & 0.39 \\
\hline Native speakers & $\mathbf{0 . 9 8}$ & 0.12 \\
\hline
\end{tabular}

As shown in Table 7, the native control group performed almost perfectly (mean 0.98) while the mean score of the Arabic learners was 0.82. An independent-samples t-test revealed that this difference in scores is significant $(t(3028.140)=-17.9, p<.001)$.

Table 8 shows the results of the Arabic learners by L1 gender type and proficiency level.

Table 8: Performance of the Arabic learners on the Grammaticality Judgment Task by 11 gender type and proficiency

\begin{tabular}{cccc}
\hline Proficiency level & $\begin{array}{c}\text {-Gender } \\
M(S D)\end{array}$ & $\begin{array}{c}+ \text { Gender } \\
M(S D)\end{array}$ & $\begin{array}{c}\text { Total } \\
M(S D)\end{array}$ \\
\hline Intermediate & $0.76(0.43)$ & $0.76(0.43)$ & $\mathbf{0 . 7 6}(0.43)$ \\
\hline Advanced & $0.86(0.35)$ & $0.88(0.32)$ & $\mathbf{0 . 8 7}(0.34)$ \\
\hline Total & $0.81(0.39)$ & $0.83(0.38)$ & $0.82(39)$ \\
\hline
\end{tabular}

A two-way ANOVA was conducted with the two independent variables being L1 gender type and proficiency level. Results showed no significant effect of L1 gender type $(F(1,2236)=0.516, p=0.473)$, but a significant effect of proficiency level $(F(1,2236)$ $=45.107, p<.001)$. As with the proficiency test, the advanced learners $(M=0.87)$ performed better than the intermediate learners $(M=0.76)$, but overall the - Gender and +Gender groups performed similarly. Again, advanced learners still did not perform as 
well as the native control group $(\mathrm{M}=.98)$ (one-way ANOVA: $F(1,2069)=89.69, p<$ .001). There was no significant interaction between L1 gender type and proficiency level $(F(1,2236)=.398, p=.528)$.

Table 9 shows the performance of Arabic learners on the Grammaticality Judgment task on two test features: tense (past vs. present), and grammaticality (grammatical vs. ungrammatical).

Table 9. Performance of the Arabic learners on the Grammaticality Judgment Task by tense and grammaticality

\begin{tabular}{|c|c|c|}
\hline Test feature & Mean & SD \\
\hline \multicolumn{3}{|l|}{ Tense } \\
\hline Past & 0.81 & 0.39 \\
\hline Present & 0.83 & 0.38 \\
\hline \multicolumn{3}{|l|}{ Grammaticality } \\
\hline Grammatical & 0.84 & 0.37 \\
\hline Ungrammatical & 0.80 & 0.39 \\
\hline
\end{tabular}

Two one-way ANOVAs revealed the following: there was a significant effect of grammaticality $(F(1,2236)=4.589, p=.032)$ but not of tense. The Arabic learners performed better on grammatical sentences $(M=.84)$ than ungrammatical ones $(M=.80)$.

Table 10 shows the mean scores on the four item types: the grammatical masculine-masculine $(\mathrm{MM})$ and feminine-feminine $(\mathrm{FF})$ verb-noun pairs, and the ungrammatical masculine-feminine (MF) and feminine-masculine (FM) verb-noun pairs. 
Table 10. Performance of the Arabic learners on the Grammaticality Judgment Task by item type

\begin{tabular}{ccc}
\hline Item Type & Mean & SD \\
\hline Grammatical & & \\
FF & $\mathbf{0 . 8 7}$ & 0.34 \\
MM & $\mathbf{0 . 8 0}$ & 0.39 \\
\hline Ungrammatical & & \\
MF & $\mathbf{0 . 8 4}$ & 0.36 \\
FM & $\mathbf{0 . 7 6}$ & 0.76 \\
\hline
\end{tabular}

A one-way ANOVA revealed that there was a significant difference overall between all four types $(F(3,2236)=8.614, p<.001)$. A post-hoc Tukey test showed a significant difference between the two grammatical ones $(p=.021)$, and between the two ungrammatical ones $(p=.002){ }^{9}$

An additional 3-way ANOVA was performed to look for interactions between subject factors (L1 gender type and proficiency) and grammaticality. Results revealed no significant interactions among these factors.

\subsubsection{Sentence Completion Task 1}

The Sentence Completion Task 1 contained 32 incomplete sentences in which participants were asked to fill in the blank with a suitable verb. Participants had to figure out whether the noun given in the sentence was masculine or feminine in order to complete the sentence with the correct verb. The required tense (16 past, 16 present) was indicated under each blank.

Table 11 shows the mean score of the Arabic learners and the native control group.

\footnotetext{
${ }^{9}$ As expected, there is also a significant difference between the highest scoring (FF) and lowest scoring $(\mathrm{FM})$ items $(p<.001)$.
} 
Table 11: Performance of the Arabic learners and native speakers on the Sentence Completion Task 1

\begin{tabular}{ccc}
\hline Participant group & Mean & SD \\
\hline Arabic learners & $\mathbf{0 . 9 0}$ & 0.31 \\
\hline Native speakers & $\mathbf{0 . 9 9}$ & 0.09 \\
\hline
\end{tabular}

As shown in Table 11, the native control group performed almost perfectly (mean 0.99) while the mean score of the Arabic learners was 0.90. An independent-samples t-test revealed that this difference in scores is significant $(t(1700.858)=-10.121, p<.001)$.

Table 12 shows the results of the Arabic learners by L1 gender type and proficiency level.

Table 12: Performance of the Arabic learners on the Sentence Completion Task 1 by L1 gender type and proficiency

\begin{tabular}{cccc}
\hline Proficiency level & $\begin{array}{c}\text {-Gender } \\
M(S D)\end{array}$ & $\begin{array}{c}+ \text { Gender } \\
M(S D)\end{array}$ & $\begin{array}{c}\text { Total } \\
M(S D)\end{array}$ \\
\hline Intermediate & $0.88(0.33)$ & $0.86(0.34)$ & $\mathbf{0 . 8 8}(0.33)$ \\
\hline Advanced & $0.90(0.30)$ & $0.93(0.25)$ & $\mathbf{0 . 9 1}(0.28)$ \\
\hline Total & $0.89(0.31)$ & $0.90(0.29)$ & $0.90(31)$ \\
\hline
\end{tabular}

A two-way ANOVA was conducted with the two independent variables being L1 gender type and proficiency level. Results showed no significant effect of L1 gender type $(F(1,1276)=0.260, p=.610)$, but a significant effect of proficiency level $(F(1,1276)=$ $5.984, p=.015)$. As with the Grammaticality Judgment Task, the advanced learners ( $M=$ 
$0.91)$ performed better than the intermediate learners $(M=0.88)$, but overall the - Gender and + Gender groups performed similarly. However, advanced learners still did not perform as well as the native control group $(M=0.99)$ (one-way ANOVA: $F(1,1181)=$ 35.357, $p<.001)$. Furthermore, there was no significant interaction between L1 gender type and proficiency level $(F(1,1276)=1.891, p=.169)$.

Table 13 shows the performance of Arabic learners on the Sentence Completion Task 1 on two test features: gender of the correct verb (masculine vs. feminine), and tense (past vs. present).

Table 13. Performance of the Arabic learners on the Sentence Completion Task 1 by gender and tense features

\begin{tabular}{|c|c|c|}
\hline Test feature & Mean & $\mathrm{SD}$ \\
\hline \multicolumn{3}{|l|}{ Gender Feature } \\
\hline Masculine & 0.94 & 0.23 \\
\hline Feminine & 0.85 & 0.36 \\
\hline \multicolumn{3}{|l|}{ Tense } \\
\hline Past & 0.91 & 0.29 \\
\hline Present & 0.88 & 0.33 \\
\hline
\end{tabular}

Two one-way ANOVAs were run examining the effect of the two test features above. These tests revealed the following: a significant effect of gender feature $(F(1$, $1278)=32.812, p<.001$ ), but not of tense. The Arabic learners performed better with masculine verbs $(M=.94)$ than with feminine verbs $(M=.85)$.

Table 14 below shows the performance of the Arabic learner groups on the Sentence Completion Task 1 by gender feature and subject factors (L1 gender type and proficiency level). 
Table 14. Performance of the Arabic learners on the Sentence Completion Task 1 by gender feature and subject factors.

\begin{tabular}{c|cc|cc|c}
\hline & \multicolumn{2}{|c|}{ L1 Gender Type } & \multicolumn{3}{c}{ Proficiency level } \\
\hline $\begin{array}{l}\text { Gender } \\
\text { Feature }\end{array}$ & $\begin{array}{c}\text {-Gender } \\
M(S D)\end{array}$ & $\begin{array}{c}\text { +Gender } \\
M(S D)\end{array}$ & $\begin{array}{c}\text { Advanced } \\
M(S D)\end{array}$ & $\begin{array}{c}\text { Intermediate } \\
M(S D)\end{array}$ & $\begin{array}{c}\text { Total } \\
M(S D)\end{array}$ \\
\hline \multirow{2}{*}{ Masculin } & $0.95(0.21)$ & $0.93(0.26)$ & $0.95(0.22)$ & $0.93(0.25)$ & $\mathbf{0 . 9 4}(0.23)$ \\
& $\mathbf{0 . 8 3}(0.34)$ & $\mathbf{0 . 8 8}(0.33)$ & $0.87(0.33)$ & $0.82(0.39)$ & $\mathbf{0 . 8 5}(0.36)$ \\
\hline Feminine & $0.89(0.31)$ & $0.90(0.29)$ & $\mathbf{0 . 9 1}(0.28)$ & $\mathbf{0 . 8 8}(0.33)$ & $0.90(0.30)$ \\
\hline
\end{tabular}

An additional 3-way ANOVA test was performed to look for interactions between gender feature and subject factors. Results revealed a significant interaction between verb gender feature and L1 gender type $(F(1,1272)=4.250, p=.039)$. That is, when the missing verb was masculine, the - Gender and + Gender groups performed similarly, but when the missing verb was feminine, the - Gender group $(M=0.83)$ did not perform as well as the + Gender group $(M=0.88)$. No significant interactions were found between verb gender feature and proficiency $(F(1,1272)=.873, p=.350)$, between L1 gender type and proficiency level $(F(1,1272)=1.942, p=.164)$, or between L1 gender type, proficiency level, and verb gender $(F(1,1272)=.077, p=.782)$.

\subsubsection{Sentence Completion Task 2}

The Sentence Completion Task 2 contained 32 incomplete sentences in which participants were asked to fill in the blank with a suitable noun. These sentences consisted of 16 missing masculine nouns, 16 missing feminine nouns, 16 verbs in the past tense, and 16 verbs in the present tense. Participants had to figure out whether the verb 
given in the sentence was masculine or feminine in order to complete the sentence with a correct noun.

Table 15 shows the mean score of the Arabic learners and the native control group.

Table 15: Performance of the Arabic learners and native speakers on the Sentence Completion Task 2

\begin{tabular}{ccc}
\hline Participant group & Mean & SD \\
\hline Arabic learners & $\mathbf{0 . 9 3}$ & 0.26 \\
\hline Native speakers & $\mathbf{1 . 0 0}$ & 0.06 \\
\hline
\end{tabular}

As shown in Table 15, the native control group performed perfectly (mean 1.00) while the mean score of the Arabic learners was 0.93. An independent-samples t-test revealed that this difference in scores is significant $(t(1619.817)=-8.682, p<.001)$.

Table 16 shows the results of the Arabic learners by L1 gender type and proficiency level. They are identical to the results of the Sentence Completion Task 1 (see Table 12 above).

Table 16 Performance of Arabic learners on the Sentence Completion Task 2 by L1 gender type and proficiency

\begin{tabular}{cccc}
\hline Proficiency Level & $\begin{array}{c}\text {-Gender } \\
M(S D)\end{array}$ & $\begin{array}{c}+ \text { Gender } \\
M(S D)\end{array}$ & $\begin{array}{c}\text { Total } \\
\text { Intermediate }\end{array}$ \\
\hline Advanced & $0.88(0.33)$ & $0.90(0.30)$ & $\mathbf{0 . 8 9}(0.32)$ \\
\hline Total & $0.96(0.20)$ & $0.97(0.16)$ & $\mathbf{0 . 9 6}(0.19)$ \\
\hline & $0.92(0.27)$ & $0.94(0.23)$ & $0.93(0.26)$ \\
\hline
\end{tabular}

A two-way ANOVA showed no significant effect of $\mathrm{L} 1$ gender type $(F(1,1276)$ $=1.627, p=0.202)$, but a significant effect of proficiency level $(F(1,1276)=25.214, \mathrm{p}$ 
$<.001)$. The advanced learners $(M=0.96)$ performed better than the intermediate learners $(M=0.89)$, but overall the - Gender and + Gender groups performed similarly. The advanced learners did not perform as well as the native control group $(M=1.00)$ (one-way ANOVA: $F(1,1182)=13.398, p<.001)$. There was no significant interaction between L1 gender type and proficiency level $(F(1,1276)=0.077, p=.782)$.

Table 17 shows the performance of Arabic learners on the Sentence Completion Task 2 on two test features: gender (masculine vs. feminine), and tense (past vs. present). Again, the results are identical to the results of the Sentence Completion Task 1 (see Table 13 above).

Table 17. Performance of the Arabic learners on the Sentence Completion Task 2 by gender and tense features

\begin{tabular}{|c|c|c|}
\hline Test feature & Mean & $\mathrm{SD}$ \\
\hline \multicolumn{3}{|l|}{ Gender Feature } \\
\hline Masculine & 0.94 & 0.23 \\
\hline Feminine & 0.91 & 0.28 \\
\hline \multicolumn{3}{|l|}{ Tense } \\
\hline Past & 0.94 & 0.25 \\
\hline Present & 0.92 & 0.27 \\
\hline
\end{tabular}

Two one-way ANOVAs revealed a significant effect of gender feature, $(F$ (1, $1278)=4.694, p=.030$ ), but not of tense. The Arabic learners performed better on masculine nouns $(M=0.94)$ than on feminine nouns $(M=.91)$.

Table 18 below shows the performance of the Arabic learner groups on the Sentence Completion Task 2 by gender feature and subject factors (L1 gender type and proficiency). 
Table 18. Performance of the Arabic learners on the Sentence Completion Task 2 by gender feature and subject factors

\begin{tabular}{c|cc|cc|c}
\hline \multirow{2}{*}{$\begin{array}{c}\text { Gender } \\
\text { Feature }\end{array}$} & \multicolumn{2}{|c|}{ L1 Gender Type } & \multicolumn{3}{c}{ Proficiency level } \\
\cline { 2 - 6 } & - Gender & + Gender & Advanced & Intermediate & Total \\
& $M(S D)$ & $M(S D)$ & $M(S D)$ & $M(S D)$ & $M(S D)$ \\
\hline Masculine & $0.94(0.24)$ & $0.96(0.21)$ & $0.96(0.19)$ & $\mathbf{0 . 9 2}(0.27)$ & $\mathbf{0 . 9 4}(0.23)$ \\
Feminine & $0.90(0.29)$ & $0.93(0.26)$ & $0.97(0.18)$ & $\mathbf{0 . 8 5}(0.36)$ & $\mathbf{0 . 9 1}(0.28)$ \\
\hline Total & $0.92(0.27)$ & $0.94(0.23)$ & $\mathbf{0 . 9 6}(0.19)$ & $\mathbf{0 . 8 9}(0.32)$ & $0.93(0.26)$ \\
\hline
\end{tabular}

An additional 3-way ANOVA test was performed to look for interactions between gender feature and subject factors. Results revealed a significant interaction between gender feature and proficiency level $(F(1,1272)=5.909, p=.015)$, which was not found in the Sentence Completion Task 1. That is, the advanced learners performed equally well on masculine $(M=0.96)$ and feminine $(M=0.97)$ nouns, while the intermediate learners performed better on masculine $(M=0.92)$ than on feminine $(M=0.85)$ nouns. No significant interactions were found between gender feature and L1 gender type ( $F$ (1, $1272)=.064, p=.800)$, between L1 gender type and proficiency level $(F(1,1272)=$ $.077, p=.781)$, or between L1 gender type, proficiency level, and gender feature ( $F(1$, $1272)=.919, p=.338)$.

\subsubsection{Picture Description Task (PDT)}

The Picture Description Task elicited a total of 1935 subject-verb pairs from the Arabic learner and native speaker groups. The number of responses differed from participant to participant, ranging from a minimum of 34 to a maximum of 43 . Responses were transcribed and evaluated based on gender agreement accuracy, with each correct pair receiving a score of one point and incorrect responses receiving zero. 
Table 19 shows the mean score of the Arabic learners and the native control group.

Table 19. Performance of the Arabic learners and native speakers on the Picture Description Task

\begin{tabular}{ccc}
\hline Participant group & Mean & SD \\
\hline Arabic learners & $\mathbf{0 . 9 1}$ & 0.28 \\
\hline Native Speakers & $\mathbf{1 . 0 0}$ & 0.00 \\
\hline
\end{tabular}

The native control group performed perfectly $(M=1.00)$, while the mean score of the Arabic learners was 0.91 . An independent-samples t-test revealed that this difference in scores is significant $(t(1289.00)=-11.124, p<.001)$.

Table 20 shows the results of the Arabic learners by L1 gender type and proficiency level.

Table 20: Performance of the Arabic learners on the Picture Description Task by L1 gender type and proficiency

\begin{tabular}{cccc}
\hline Proficiency Level & $\begin{array}{c}\text {-Gender } \\
M(S D)\end{array}$ & $\begin{array}{c}+ \text { Gender } \\
M(S D)\end{array}$ & $\begin{array}{c}\text { Total } \\
M(S D)\end{array}$ \\
\hline Intermediate & $0.88(0.33)$ & $0.90(0.30)$ & $\mathbf{0 . 8 8}(0.32)$ \\
\hline Advanced & $0.93(0.27)$ & $0.95(0.22)$ & $\mathbf{0 . 9 4}(0.24)$ \\
\hline Total & $0.90(0.29)$ & $0.93(0.26)$ & $0.91(0.82)$ \\
\hline
\end{tabular}

A two-way ANOVA was conducted with the two independent variables being L1 gender type and proficiency level. As with all previous tasks, results showed no significant effect of L1 gender type $(F(1,1286)=1.117, p=.291)$, but a significant 
effect of proficiency level $(F(1,1286)=8.450, p=.004)$. That is, advanced learners $(M$ $=0.94)$ performed better than the intermediate learners $(M=0.88)$, but overall the Gender and + Gender groups performed similarly. Again, the advanced learners did not perform as well as the native control group $(M=1.00)$ (one-way ANOVA: $F(1,1336)=$ 43.663, $p<.001)$. Furthermore, there was no significant interaction between L1 gender type and proficiency level $(F(1,1286)=.001, p=.979)$.

Table 21 shows the performance of Arabic learners on the Picture Description Task on the one test feature analyzed: gender (masculine vs. feminine).

Table 21. Performance of the Arabic learners on the Picture Description Task by gender feature

\begin{tabular}{rll}
\hline Test feature & Mean & SD \\
\hline Gender Feature & & \\
Masculine & $\mathbf{0 . 9 5}$ & 0.21 \\
Feminine & $\mathbf{0 . 8 7}$ & 0.34 \\
\hline
\end{tabular}

A one-way ANOVA showed a significant effect of gender feature, $(F(1,1288)=$ 30.215, $p<.001)$. That is, the Arabic learners performed significantly better with masculine $(M=0.95)$ than with feminine $(M=0.87)$ pairs. An additional 3-way ANOVA test revealed no interactions between gender and subject factors (L1 gender type and proficiency). 
5.2.5 Comprehension vs. Production

Table 22 summarizes the Arabic learners' performance on the four experimental tasks: Grammaticality Judgment, Sentence Completion 1, Sentence Completion 2, and Picture Description. The Grammaticality Judgment Task is a comprehension task, while the other three are production tasks.

Table 22. Performance of the Arabic learners on the experimental tasks

\begin{tabular}{cccc}
\hline Experimental task & Task Type & Mean & SD \\
\hline Grammaticality Judgment & Comprehension & 0.82 & 0.39 \\
\hline Sentence Completion 1 & Production & 0.90 & 0.31 \\
\hline Sentence Completion 2 & Production & 0.93 & 0.26 \\
\hline Picture Description & Production & 0.91 & 0.28 \\
\hline
\end{tabular}

As shown in Table 22, the mean of the Grammaticality Judgment Task is lower than that of the other three tasks. A one-way ANOVA revealed a significant difference in performance between all the tasks, $F(3,6086)=40.786, p<.001$. A post-hoc Tukey HSD revealed a significant difference between the Grammaticality Judgment Task (comprehension) and each production task at $p<.001$, and no differences between the three production tasks. 


\section{Chapter 6: Discussion}

The experimental tasks in this study investigated the acquisition of Arabic grammatical gender, specifically, subject-verb gender agreement in adult second language learners of Arabic from different L1 backgrounds. The Arabic learners were divided into two groups, -Gender and +Gender, based on whether or not their L1 has a grammatical gender system. The reason for having these two groups was to determine how the native language could positively or negatively affect grammatical gender acquisition in the L2. Moreover, comparing -Gender and +Gender groups could provide some evidence about whether or not the principles and parameters of UG are involved in the process of SLA. The results of this study will be discussed in light of the research questions presented in section 3.3 above, divided into four sections: subject performance, FTFA versus FFFH, experimental tasks, and learners' L1.

\subsection{Subject Performance}

Research questions 1-3 focused on the acquisition of subject-verb gender agreement in the various participant groups and subgroups. The answers to these questions are as follows:

$R Q$ 1: Can the Arabic learner groups acquire Arabic verb-subject gender agreement as accurately as the native control group?

No, the Arabic learners did not perform as accurately as the native control group. This result was highly consistent across all tasks and all Arabic learner subgroups.

$R Q$ 2: Among the L2 learners, can the -Gender groups acquire Arabic verbsubject gender agreement as accurately as the +Gender groups? 
Yes, the -Gender group was able to acquire subject-verb gender agreement as well as the +Gender group. This result was highly consistent for both proficiency levels and across all experimental tasks.

$R Q 3:$ Will level of proficiency affect the acquisition of gender?

Yes, proficiency level had a significant effect on the Arabic learners' performance. Advanced learners from both -Gender and +Gender groups outperformed the intermediate learners in all experimental tasks.

With regard to question 1 , the difference in performance between the Arabic learners and the native speakers was expected even at the advanced level since the participants of this study were still learning Arabic and they had not reached target-like performance. However, upon closer examination, it was found that some individual learners did perform as well as native speakers. Table 23 below shows the number and percentage of the individual Arabic learners who performed within the same scoring range as native speakers.

Table 23. Percentage of participants who scored within the same range as native speakers on each task

\begin{tabular}{c|c|c|c}
\hline Task & $\begin{array}{c}\text { Native speakers } \\
\text { score range }\end{array}$ & $\begin{array}{c}\text { Native speakers } \\
(\mathrm{n}=15)\end{array}$ & $\begin{array}{c}\text { Arabic learners } \\
(\mathrm{n}=40)\end{array}$ \\
\hline $\begin{array}{c}\text { Grammaticality } \\
\text { Judgment }\end{array}$ & $96.42-100 \%$ & $\begin{array}{c}(\mathrm{n}=15) \\
100 \%\end{array}$ & $\begin{array}{c}(\mathrm{n}=3) \\
7.5 \%\end{array}$ \\
\hline Sentence Completion 1 & $96.87 \%-100 \%$ & $\begin{array}{c}(\mathrm{n}=14)^{*} \\
100 \%\end{array}$ & $\begin{array}{c}(\mathrm{n}=16) \\
40 \%\end{array}$ \\
\hline Sentence Completion 2 & $100 \%$ & $\begin{array}{c}(\mathrm{n}=15) \\
100 \%\end{array}$ & $\begin{array}{c}(\mathrm{n}=18) \\
45 \%\end{array}$ \\
\hline Picture Description $^{* *}$ & $100 \%$ & $\begin{array}{c}(\mathrm{n}=15) \\
100 \%\end{array}$ & $\begin{array}{c}(\mathrm{n}=9) \\
22.5 \%\end{array}$ \\
\hline
\end{tabular}

* One native speaker is not included in the native speaker range because his score was $93.75 \%$ due to leaving 2 questions blank.

** The total number of Arabic learners performing the Picture Description task was 33 (22 Gender and $11+$ Gender). 
As shown in Table 23, the number of Arabic learners who scored similarly to the native speaker control group ranged from $7.5-45 \%$ depending on the task. Both Gender and + Gender groups were represented on all the tasks. It can be argued that attaining native-like performance in Arabic is still possible for the Arabic learner participants.

Within the Arabic learner groups, although results showed significant differences between intermediate and advanced learners, in each task there was at least one intermediate learner who scored in the same range as the best performing advanced learners. Several studies that investigated Arabic SLA have reported that Arabic verbal gender agreement is one of the linguistic structures that are acquired at early stages (e.g. Nielsen, 1997; Alhawary, 1999, 2003; Mansouri, 2000, 2005). For example, Alhawary (2003) examined the acquisition of Arabic gender agreement in the third personal singular by beginner L2 Arabic learners. All learners were native speakers of English. He points out that the majority of participants (6 out of 9 ) acquired subject-verb agreement before noun-adjective agreement. This might explain the high performance of the intermediate individuals in the present study, as it is possible that they had acquired subject-verb gender agreement sometime before the administration of the tasks. 


\subsection{FTFA vs. FFFH}

Research Question 4 explores how the answers to questions 1-3 are consistent or inconsistent with two hypotheses: FTFA and FFFH.

$R Q 4:$ Will the results support the FTFA or FFFH hypotheses?

The results of this study showed the following: 1) the Arabic learners did not reach native speakers' level of performance; 2) the -Gender group performed similarly to the + Gender group at each proficiency level; and 3) advanced learners performed better than intermediate learners. The second result supports a Full Access account of second language acquisition, since the -Gender group was able to reset their L1 parameter according to the L2 gender values. As for L1 transfer, the results suggest that this effect may be found at the initial and earlier stages of acquisition, but disappears as the learners reach the intermediate and advanced levels in their development and progress toward the target language. Table 24 compares the results of the present study with the predications of the FTFA and FFFH.

Table 24. Predictions of FTFA and FFFH with results of this study

\begin{tabular}{l|l|l|l}
\hline Case & FTFA & FFFH & Results of this study \\
\hline $\begin{array}{c}\text { 1. Arabic learners } \\
\text { vs. } \\
\text { Native speakers }\end{array}$ & NS $=$ Adv & NS $=$ Adv $+\mathrm{G}$ & NS $>$ Adv \\
\hline $\begin{array}{c}\text { 2. -Gender vs. } \\
+ \text { Gender }\end{array}$ & Adv $-\mathbf{G}=\mathbf{A d v}+\mathbf{G}$ & Adv $+\mathrm{G}>\mathrm{Adv}-\mathrm{G}$ & Adv $-\mathbf{G}=$ Adv. $+\mathbf{G}$ \\
\cline { 2 - 4 } & Interm $+\mathbf{G}>$ ? Interm $-\mathbf{G}$ & Interm $+\mathrm{G}>$ Interm $-\mathrm{G}$ & Interm $+\mathbf{G}=$ Interm $-\mathbf{G}$ \\
\hline $\begin{array}{c}\text { 3. Advanced vs. } \\
\text { Intermediate }\end{array}$ & Adv $>$ Interm & NA & Adv $>$ Interm \\
\hline
\end{tabular}


The Arabic learners in this study did not perform as well as the native speakers, which is inconsistent with both the FTFA and FFFH hypotheses. However, both the FTFA and FFFH are concerned with L2 learners' end state of acquisition. As mentioned above, the advanced participants in this study are still in the process of learning Arabic, and it cannot be claimed that as a group they have reached their final state of acquisition. For this reason, their performance does not support either of the hypotheses. However, the results of those individual learners who performed as well as native speakers (See Table 22) could lend some support to the prediction of the FTFA. Several studies in the literature have provided findings in favor of the FTFA hypothesis, where L2 learners were able to acquire the L2 grammatical gender system despite not having a similar structure in their L1 (e.g. White et al, 2004; Bolotin, 1996a; Bond et al., 2011; Alhawary, 2005, 2009).

The FTFA predicts that at the advanced proficiency level both -Gender and +Gender groups would perform similarly. The results of this study support this prediction. At the intermediate level the FTFA predicts that the + Gender group might outperform the intermediate -Gender group due to L1 transfer. In this study there was no difference in the overall performance of the -Gender and +Gender groups, thus supporting the FTFA prediction. These findings align with White et al's (2004) study of Spanish grammatical gender acquisition by L2 learners from different L1 backgrounds and proficiency levels. They found that there was no effect of L1, even at low proficiency levels. Bolotin (1996a) and Alhawary $(2005,2009)$ provide similar results to this study where L2 learners with no gender system in their L1s were able to acquire L2 grammatical gender as well as those learners with gender system in their L1s. In the 
present study there was, however, one case where an L1 effect was found: in the Sentence Completion Task 1, +Gender learners were better than -Gender learners in filling in feminine nouns correctly (See Table 14).

Overall, on the production tasks the participants performed better on masculine rather than feminine items. This can be seen in Table 13 for the Sentence Completion Task 1, in Table 17 for the Sentence Completion Task 2, and in Table 21 for the Picture Description Task. This preference of masculine over feminine is reasonable as masculine in Arabic is the default form. Moreover, in the case of the third person, which is the focus of the study, the masculine agreement morpheme is null, which also might explain why learners found using or identifying the masculine form easier than using the feminine form. Even though on the Sentence Completion Task 1 the + Gender group performed better the -Gender group on feminine verbs, both groups performed better on the masculine forms. Alhawary (2009) also found that participants were using masculine as the default, as they had higher correct answers on masculine rather than on feminine items on his production tasks. Other studies have also reported that L2 learners tend to use one gender (masculine or feminine) as a default (e.g. White et al, 2004; Sabourin et al, 2006).

Despite the general preference for masculine over feminine forms, in the Grammaticality Judgment Task the Arabic learners performed better on femininefeminine (i.e., feminine verb and feminine noun) pairs rather than on masculinemasculine (masculine verb and masculine noun) pairs. That is, they accepted more feminine-feminine items than masculine-masculine items as being grammatical. This could be due to a 'yes'-bias effect, which is that participants tend to choose the 'correct' 
option when they are not sure what the correct answer is (Sabourin et al., 2006). This is supported by the Arabic learners' responses to the ungrammatical sentences, where they accepted more ungrammatical feminine-masculine items (that is, feminine verb and masculine noun) than masculine-feminine ones (See Table 10).

Finally, the FTFA predicts that both advanced + Gender and - Gender groups will outperform both intermediate learner groups due to the greater amount of L2 input that advanced learners are exposed to. This prediction was supported by the results of this study.

The results of this study do not support the FFFH, as this hypothesis claims that learners' L1 will determine the acquisition of the L2 gender system, and thus the + Gender group will outperform the -Gender group at all stages of development.

\subsection{Experimental Tasks}

This section discusses the differences and similarities between experimental tasks in this study.

$R Q$ 5: Will there be a difference in performance on comprehension and production tasks?

Yes, there was a significant difference between the Arabic learners' performance on the comprehension task (Grammaticality Judgment) and the production tasks (Sentence Completion 1, Sentence Completion 2, and Picture Description). Table 22 (repeated here as Table 25) compares the means of the Arabic learners on the comprehension and production tasks. 
Table 25. The Arabic learners' performance on the experimental tasks

\begin{tabular}{cccc}
\hline Experimental task & Task Type & Mean & SD \\
\hline Grammaticality Judgment & Comprehension & 0.82 & 0.385 \\
\hline Sentence Completion 1 & Production & 0.90 & 0.306 \\
\hline Sentence Completion 2 & Production & 0.93 & 0.258 \\
\hline Picture Description & Production & 0.91 & 0.283 \\
\hline
\end{tabular}

The Grammaticality Judgment Task was more problematic for the Arabic learners than the other tasks. This, in fact, is unexpected since it has always been assumed that comprehension precedes production during the process of language development (Krashen \& Terrell, 1983) and that L2 learners can normally comprehend much more than they can produce in a second language. However, in the case of the Grammaticality Judgment Task, the complexity of the intuitional process makes this task quite difficult (Sorace, 1996). The participants must read the sentences, make judgments, and underline the incorrect part, so in order to complete the task they needed to focus on every word in the sentence. In contrast, in the Sentence Completion Tasks, they were asked to fill in the blank with a verb (Task 1) or a noun (Task 2), so they only had to focus on the blank and the preceding or following word. In the Picture Description Task, participants were asked to describe pictures in which different people were doing different actions, so participants only had to think of a suitable verb. Previous studies have reported differences between Grammaticality Judgment Tasks and production tasks, in which L2 learners' scores were lower in the Grammaticality Judgment Tasks (e.g. Kellerman, 1985; Liceras, 1983; Ellis, 1991). 
Although the Grammaticality Judgment Task has been widely used in the field of SLA, there have been many research concerns about the validity and reliability of this task, and whether this kind of tool reflects L2 learner's grammatical competence (e.g. Birdsong, 1989, 1992; Sorace, 1996). Mackey and Gass (2005) highlight a very important point regarding grammaticality judgment tasks. They state that "'native speakers' judgment are tapping a system that the individual has command over, [while] this is not the case with nonnative speakers, who are being asked about the second language while inferences are being made about another system: their interlanguage" (p. 50). On the other hand, this task can provide insight into whether the participants know that certain forms are ungrammatical in Arabic languages, and thus help to "find out whether sentences which are ruled out by principles of UG are also disallowed in the interlanguage grammar" (White, 2003, p. 18). The Arabic learners in this study had more correct answers when the sentence was grammatical than when it was ungrammatical (See Table 9), which suggests that some ungrammatical sentences were part of their interlanguage.

Within the production tasks, it was found that there was no significant difference between learners' performance in the written production tasks (Sentence Completion 1 and 2) and the oral production task (Picture Description). As shown in Table 25, the highest performing score by the Arabic learners was in the Sentence Completion Task 2 $(M=.93)$. This task was the easiest one among all the experimental tasks, because it simply required participants to fill in the gap with a noun of the proper gender. They were instructed not to spend much time thinking of a good noun; hence, they were allowed to use the same noun multiple times. So, for instance, if a participant used the noun 
"Ahmed" in every question that required a masculine noun, it was considered to be correct in all cases.

\subsection{Learners' L1}

Although this study included L2 learners from different L1 background, it is not possible to make any generalizations based on subgroups of L1 learner types since the majority of the -Gender languages belonged to the Malayo-Polynesian family, and most of the + Gender languages belonged to the Indo- Iranian/Indo-Aryan family (See Table 26).

Table 26 The Arabic learners by L1 language family

\begin{tabular}{|c|c|c|}
\hline Group & L1 language family & Num. of speakers \\
\hline \multirow{3}{*}{$\begin{array}{l}\text {-Gender } \\
(\mathrm{n}=26)\end{array}$} & Malayo-Polynesian & 17 \\
\hline & Sino- Tibetan/ Chinese & 5 \\
\hline & Turkic & 4 \\
\hline \multirow{2}{*}{$\begin{array}{l}\text { +Gender } \\
(\mathrm{n}=14)\end{array}$} & Indo- Iranian/ Indo-Aryan & 12 \\
\hline & Romance & 2 \\
\hline
\end{tabular}




\subsection{Directions for further research}

Despite the fact that the acquisition of grammatical gender has been widely investigated in many languages, only a few studies have been devoted to investigating this issue in Arabic SLA. Bearing in mind the richness of Arabic morphology and syntax in general and grammatical gender in particular, future research on the acquisition of gender in Arabic might bring more insights into the field of second language acquisition. However, future research should extend its scope in terms of the morphological and syntactic structures to be investigated, the types of tasks to be used and the participants to be tested.

Previous research on grammatical gender in Arabic SLA has mainly used traditional behavioral tasks (e.g. Alhawary, 2005, 2009; Nielsen, 1997). Therefore, future research is encouraged to incorporate different methodologies to investigate this issue. These might include an on-line grammaticality judgment task, ERP experiments and visual world paradigms in order to explore the implicit knowledge of Arabic L2 learners and better understand the processing dynamics of gender acquisition. Previous research in other languages have confirmed the importance of combining different methods in investigating gender acquisition as a means of validating and refining the current frameworks and theories of SLA (Sabourin, 2003; Bond et al. 2011). Ellis (2004) argues that timed-tasks, such as on-line grammaticality judgment tasks, are used to examine the learners' implicit knowledge, while off-line grammaticality judgments tasks are used to examine their explicit knowledge. 
Another direction for future research is to examine the acquisition of grammatical gender in a variety of structures. Gender agreement in Arabic can be investigated in many different structures including noun and adjective, demonstrative pronouns, and relative pronouns. Subject and verb gender agreement, which is the focus of the current study, could also be examined with subjects in different Cases (nominative, accusative) and persons (first, second, and third). Future research might also explore gender acquisition in local and long-distance dependency structures, and the memory costs associated with long-distance dependencies.

Finally, future research should consider the quality of the participants in terms of their level of proficiency, gender and age. All these factors could have various impacts on the results to be obtained. The majority of studies that have been conducted on Arabic gender, including the current study, administered their tasks on participants who were in the middle of the process of learning Arabic, without having a participant group of highly proficient Arabic L2 learners who are at or close to their end states of acquisition. This makes it hard to provide confident claims for or against current SLA theories. Future research is hence recommended to replicate studies conducted in different languages that have controlled for such issues. For example, White et al.'s (2004) research included beginner, intermediate, and advanced learners. The advanced group was so highly proficient that there were no significant differences between their performance and the performance of the native speaker control group. This gave the authors of the study the confidence to support the full access hypothesis. Similar studies with a range of participant groups are needed to investigate gender acquisition in Arabic. 


\section{References}

Abu Radwan, A. (2002). "Sentence Processing Strategies: An application of the Competition Model to Arabic". In D. Parkinson and E. Benmamoun (Eds.), Perspectives on Arabic Linguistics, (185-209). Amsterdam. The Metherlands: John Benjamins.

Al-Ani, S. H. (1973). "Features of Interference in the Teaching of Arabic Composition". An-Nashra, V-VI, 3-13.

Al-Buainain, H. (1986). Second Language Acquisition of Arabic: The development of negation and interrogation among learners in the UK. Ph.D. dissertation, University of Edinburgh. Qatar: Dar Al-Taqafa (1988).

Al-Buainain, H. (1991). "Universality of Language Acquisition Processes in a Study of the IL of a Group of Students of Arabic". International Review of Applied Linguistics. 93, 25-69.

Alhawary, M. T. (2003). Processability theory: Counter-evidence from Arabic second language acquisition data. Al-Arabiya, 36, 107-166.

Alhawary, M. T. (2005). L2 acquisition of Arabic morphosyntactic features: Temporary or permanent impairment? In M. T. Alhawary \& E. Benmamoun (Eds.), Perspectives on Arabic linguistics, (pp. 273-312). Amsterdam: John Benjamins.

Alhawary, M. T. (2009). Arabic Second Language Acquisition of Morphosyntax. Yale University Press.

Birdsong, D. (1989). Metalinguistic performance and interlinguistic competence. Berlin: Springer-Verlag.

Birdsong, D. (1992). Ultimate attainment in second language acquisition. Language, 68, 706-55.

Bley-Vroman, R. (1989). What is the logical problem of foreign language learning? In S. Gass \& J. Schacter (Eds.), Linguistic perspectives on second language acquisition (pp. 41-68). Cambridge: Cambridge University Press.

Bley-Vroman, R. (1990). The logical problem of foreign language learning. Linguistic Analysis, 20, 3-49.

Blom, E., D. Polišenská and Unsworth, S. (2008). The acquisition of grammatical gender in Dutch. Second Language Research, 24(3), 259-265.

Bolotin, N. (1996a). "Resetting Parameters in Acquiring Arabic”. In M. Eid and D. Parkinson (Eds.), Perspectives on Arabic Linguistics, (pp. 166-178). Amsterdam. The Metherlands: John Benjamins. 
Bond, K., Gabriele, A., Fiorentino, R., and Banon, J. A. (2011). Individual Differences and the Role of the L1 in L2 Processing: An ERP Investigation. In J.

Herschensohn and D. (Eds.), Tanner Proceedings of the $11^{\text {th }}$ Generative Approaches to Second Language Acquisition Conference GASLA, (pp. 17-29). Somerville, MA: Cascadilla Proceedings Project.

Chomsky, N. (1965). Aspects of the Theory of Syntax. Cambridge, MA: MIT Press.

Chomsky, N. (1980). Rules and Representations. Oxford: Basil Blackwell.

Chomsky, N. (1981a). Lectures on Government and Binding. Dordrecht: Foris.

Chomsky, N. (1981b). "Principles and parameters in syntactic theory." In:

N. Hornstein and D. Lightfoot (Eds.), Explanation in linguistics: The logical problem of language acquisition. Longman.

Clahsen, H., \& Muysken, P. (1986). The availability of universal grammar to adult and child learners: A study of the acquisition of German word order. Second Language Research, 2, 93-119.

Clahsen, H. (1990). Constraints on parameter setting: A grammatical analysis of some acquisition stages in German child language. Language Acquisition, 1, 361-391.

Clahsen, H.and Hong, U. (1995). "Agreement and null subject in German L2 development: new evidence from reaction-time experiment". Second Language Research 11 (1), 57 - 89.

Corbett, G (1991). Gender. Cambridge: Cambridge University Press.

Cornips, L. and Hulk, A. (2008). Factors of success and failure in the acquisition of grammatical gender in Dutch. Second Language Research, 24(4), 267-295.

Dewaele, J. M., \& Véronique, D. (2001). Gender assignment and gender agreement in advanced French interlanguage: a cross-sectional study. Bilingualism: Language and Cognition, (4), 275-297.

Dugarova, E. (2007). Acquisition of the Chinese reflexive 'ziji' by Russian and English Speakers. In N. Hilton et al. (Eds.), Proceedings of the Fifth University of Cambridge Postgraduate Conference in Language Research. Cambridge Institute of Language Research.

Ellis, C., Conardie, S., and Huddlestone, K. (2012). The acquisition of grammatical gender in L2 German by learners with Afrikaans, English or Italian as their L1. Stellenbosch Papers in Linguistics, 41, 17-27.

Ellis, R. (1991). Grammaticality judgements and second language acquisition. Studies in Second Language Acquisition, 13 (3), 161-186. 
Epstein, S.D., Flynn, S. and Martohardjono, G. (1996). "Second language acquisition: theoretical and experimental issues in contemporary research." Behavioral and Brain Sciences, 19, 677-758.

Eubank, L. (1996). "Negation in early German-English Interlanguage: more Valueless Features in the L2 initial state." Second Language Research 12 (1), 73-106.

Eubank, L., Bischof, J., Huffstutler, A., Leek, P. and West, C. (1997). “Tom eats slowly cooked eggs": thematic-verb raising in L2 knowledge. Language Acquisition, 6, 171-199.

Finneman, M.D. (1992). Learning agreement in the noun phrase: the strategies of three first-year Spanish students. IRAL, 30, 121-36.

Flynn, S. (1996). A parameter setting to second language acquisition. In Ritchie, W. and Bhatia, T., editors, Handbook of second language acquisition. New York: Academic Press, 121-58.

Franceschina, F. (2001). Morphological or syntactic deficits in near-native speakers? An assessment of some current proposals. Second Language Research, 17, 213-247.

Franceschina, F. (2002). Case and $\Phi$-feature agreement in advanced L2 Spanish grammars. EUROSLA Yearbook, 2, 71-86.

Franceschina, F. (2005). Fossilized Second Language Grammars. Amsterdam: JohnBenjamins.

Friederici, A. D., and Jacobsen, T. (1999). Processing grammatical gender during language comprehension. Journal of Psycholinguistic Research, 28(5), 467-484.

Gass, S. and L. Selinker (Eds.) (1983). Language transfer in language learning. Rowley, Mass.: Newbury House.

Håkansson, G. (2001) Against Full Transfer - evidence from Swedish learners of German. Working Papers, 48, 67-86.

Hawkins, R., \& Chan, C. Y.-H. (1997). The partial availability of Universal Grammar in second language acquisition: The "failed functional features hypothesis." Second Language Research, 13, 187-226.

Hawkins, R. (1998). Explaining the difficulty of French gender attribution for speakers of English. Paper presented at the 8th annual EUROSLA conference, Paris.

Haznedar, B. (1997). L2 acquisition by a Turkish-speaking child: Evidence for L1 influence. In E. Hughes, M. Hughes, \& A. Greenhill (Eds.), Proceedings of the 21st Annual Boston University Conference on Language Development (pp. 245256). Somerville, MA: Cascadilla Press. 
Hockett, C.F. (1958). A Course in Modern Linguistics. New York: Macmillan.

Hulk, A. (1991). "Parameter setting and the acquisition of word order in L2 French." Second Language Research, 7, 1-34.

Jansen, B., Lalleman, J., and Muysken, P. (1981). "The alternation hypothesis: acquisition of Dutch word order by Turkish and Moroccan foreign workers." Language Learning, 31, 315-36.

Kellerman, E. (1985). Dative alternation and the analysis of data: A reply to Mazurkewich. Language Learning, 55, 91-101.

Krashen, S. D. and Tracy D. T. (1983). The natural approach: Language acquisition in the classroom. Hayward, CA: Alemany Press.

Lado, R. (1957). Linguistics Across Cultures. Applied Linguistics for Language Teachers. Ann Arbor. University of Michigan Press.

Liceras, M. J. (1983). Markedness, contrastive analysis and the acquisition of Spanish syntax by English speakers. Ph.D. dissertation, University of Toronto.

Mackey, A., and Gass, S. M. (2005). Second language research: Methodology and design. Mahwah, NJ: Lawrence Erlbaum Associates.

Mansouri, F. (1995). The Acquisition of Subject-Verb Agreement in Arabic as a Second Language. ARAL, 18 (2), 65-84.

Mansouri, F. (2000). Grammatical Markedness and Information Processing in the Acquisition of Arabic L2. Munich, Germany: Lincom Europa.

McCarthy, C. (2008). Morphological variability in the comprehension of agreement: An argument for representation over computation. Second Language Research, 24, 459-486.

Meisel, J., Clahsen, H. and Pienemann, M. (1981). "On determining developmental stages in natural second language acquisition." Studies in Second Language Acquisition 3 (2): 109-35.

Meisel, J. (1997). "The acquisition of negation in French and German: contrasting first and second language development." Second Language Research, 13 (3): 227-264.

Montrul, S., Foote, R., \& Perpiñán, S. (2008). Gender agreement in adult second language learners and Spanish heritage speakers: The effects of age and context of acquisition. Language Learning, 58(3), 503-553.

Nielsen, H. L. (1997). "On Acquisition of Order of Agreement Procedures in Arabic Learner Language". Al-Arabiya, 30, 49-93. 
Odlin, T. (1989). Language Transfer. Cambridge: Cambridge University Press.

Odlin, T (1993). Language Transfer: Cross-linguistic Influence in Language Learning. Cambridge, CUP.

Odlin, T. (2003). Cross-linguistic Influence. In C. J. Doughty and M. H. Long (Eds.) The Handbook of Second Language Acquisition, Oxford: Blackwell Publishing, 436486.

Oliphant, K. (1998). Acquisition of grammatical gender in Italian as a foreign language. The Canadian Modern Language Review/La Revue Canadienne Des Langues Vivantes, 54(2), 239-262.

Pienemann, M. (1998). Language Processing and Second Language Development: Processability Theory. Amsterdam. The Metherlands: John Benjamins.

Platzack, C. (1996). "The initial hypothesis of syntax: a minimalist perspective on language acquisition and attrition." In: H. Clahsen (Ed.), Generative perspectives on language acquisition: empirical findings, theoretical considerations, crosslinguistic comparisons. Amsterdam/Philadelpia: Benjamins.

Rammuny, R. (1979). "Statistical Study of American Students in Written Arabic". AlArabiya, 9, 75-94.

Rogers, M. (1987). Learners' difficulties with grammatical gender in German as a foreign language. Applied Linguistics, 8, 48-74.

Sabourin, L., Stowe L. A. \& de Haan G. J. (2006). Transfer effects in learning a second language grammatical gender system. Second Language Research, 22(1), 1-29.

Sabourin, L. (2001). L1 effects on the processing of grammatical gender in L2. Eurosla yearbook, 1(1), 159-169.

Sabourin, Laura. (2003). Grammatical Gender and Second Language Processing: An ERP study. Ms., GRODIL: Groningen Dissertations in Linguistics, 42.

Schachter, J. (1989). Testing a proposed universal. In S. Gass \& J. Schacter (Eds.) Linguistic perspectives on second language acquisition (pp. 73-88). Cambridge: Cambridge University Press.

Schachter, J. (1990). "On the issue of completeness." Second Language Research, 6, 93124.

Schwartz, B. D., \& Sprouse, R. (1994). Word order and nominative case in nonnative language acquisition. In T. Hoekstra \& B. Schwartz (Eds.), Language acquisition studies in generative grammar (pp. 317-368). Amsterdam: John Benjamins. 
Schwartz, B.D. \& Sprouse, R. (1996). L2 cognitive states and the full transfer/full access model. Second Language Research, 12(1), 40-72.

Schwartz, B. (1998). The second language instinct. Lingua, 106, 133-160.

Slabakova, R. (2000). L1 transfer revisited: The L2 acquisition of telicity marking in English by Spanish and Bulgarian native speakers. Linguistics, 38, 739-770.

Smith, N., \& Tsimpli, I.-M. (1995). The mind of a savant: language learning and modularity. Oxford: Blackwell.

Sorace, A. (1996). The use of acceptability judgments in second language acquisition research. In W. Ritchie \& T. Bhatia (Eds.), Handbook of second language acquisition (pp. 375-409). San Diego, CA: Academic Press.

Tsimpli, I. M., \& Roussou, A. (1991). Parameter resetting in L2?. UCL Working Paper in Linguistics, 3, 149-169.

Tsimpli, I. M., \& Mastropavlou, M. (2007). Feature interpretability in L2 acquisition and SLI: Greek clitics and determiners. In J. Liceras, H. Zobl, \& H. Goodluck, (Eds.), The Role of Formal Features in Second Language Acquisition. Mahwah, NJ: Lawrence Erlbaum.

Vainikka, A. and Young-Scholten, M. (1994). "Direct access to X'-theory: evidence from Korean and Turkish adult learning German". In: T. Hoekstra, and B. Schwartz (Eds.), Language acquisition in generative grammar. Amsterdam/Philadelpia: Benjamins.

Vainikka, A. and Young-Scholten, M. (1996a). "Gradual development of L2 phrase structure." Second Language Research 12, 7-39.

Vainikka, A. and Young-Scholten, M. (1996b). The early stages in adult L2 syntax: Additional evidence from Romance speakers. Second Language Research, 12, 140-176.

White, L. (1985a). The acquisition of parameterized grammar: subjacency in second language acquisition. Second Language Research, 1 (1), 1-17.

White, L. (1985b). The pro-drop parameter in adult second language acquisition. Language Learning, 35 (1), 47-61.

White, L. (1989) Universal grammar and second language acquisition. Amsterdam: John Benjamins.

White, L. (1990). Second language acquisition and universal grammar. Studies in Second Language Acquisition, 12, 121-133. 
White, L. (1991a). Adverb placement in second language acquisition: some effects of positive and negative evidence in the classroom. Second Language Research, 7, 133-61.

White, L. (1991b). The verb movement parameter in second language acquisition. Language Acquisition, 1, 337-60.

White, L. (1992). Long and short verb movement in second language acquisition. Canadian Journal of Linguistics, 37, 273-86.

White, L. (1993). 'Universal Grammar: Is it just a new name for old problems?' In S. Gass \& L. Selinker (eds), Language transfer in language learning, (pp. 217-32). Rowley, Mass.: Newbury House.

White, L. (2003). Second language acquisition and universal grammar. Cambridge University Press.

White, L., Valenzuela, E., Kozlowska-MacGregor, M., \& Leung, Y. I. (2004). Gender and number agreement in nonnative Spanish. Applied Psycholinguistics, 25(1), 105-133.

Whong-Barr, M. (2006). "What transfers?". In S. Unsworth, T. Parodi, A. Sorace, and M. Young-Scholten (Eds.) Paths of Development in L1 and L2 Acquisition (pp. 187199), Amsterdam: John Benjamins Publishing Company.

Yuan, B. (1998). Interpretation of binding and orientation of the Chinese reflexive ziji by English and Japanese speakers. Second Language Research, 14, 324-340. 


\section{Appendices}

\section{Appendix A: Grammaticality Judgment Task}

\section{Grammatical: Masculine verb - Masculine subject, Past tense}

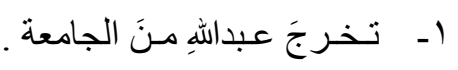

1- 'Abdullah m.s. graduated m.s. from the university.'

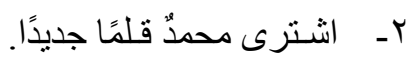

2- 'Mohammad m.s. bought m.s. a new pen.'

$$
\text { r- حضرَ الأميرُ في تو اضعٍ. }
$$

3- 'The prince m.s. attended m.s. with humbleness.'

$$
\text { ــ ـ أعطى الأبُ الطفلَ هديةُ. }
$$

4- 'The father m.s. gave m.s. the child a gift.'

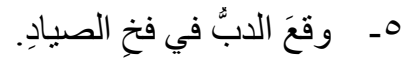

5- 'The bear m.s. fell m.s. into the hunter trap'

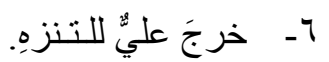

6- 'Ali m.s. went m.s. out for a picnic.'

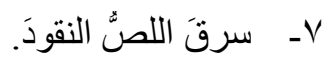

7- 'The thief m.s. stole m.s. the money'

\section{Grammatical: Feminine verb - Feminine subject, Past tense}

$$
\text { 1 - كرمت المديرةُ الطالباتِ المتفوقات. }
$$

1- 'The principal f.s. lionized f.s. the outstanding students.'

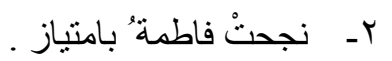

2- 'Fatimah f.s. passed f.s. with excellence.'

$$
\text { r- شرحت المعلمةُ الدرسَ بوضوحٍ. }
$$

3- 'The teacher f.s. explained f.s. the lesson clearly.'

$$
\text { ع - منعت الطبيبة المريضََ من أكلِ اللحوِم. }
$$

4- 'The doctor f.s. prevented f.s the sick man from eating meats.' 


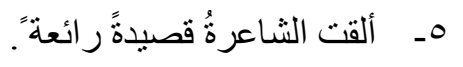

5- 'The poet f.s. recited f.s. wonderful poem.'

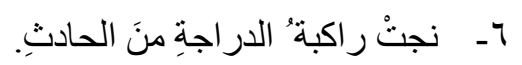

6- 'The cyclist f.s. survived f.s. from the accident.'

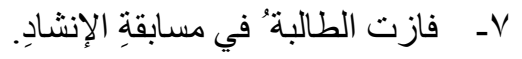

7- 'The student f.s. won f.s. in the singing competition.'

\section{Grammatical: Masculine verb - Masculine subject, Present tense}

$$
\text { ا - يذهبُ الولدُ إلى الطبِيب كلَّ شهر. }
$$

1- 'The son m.s. goes m.s. to the doctor every month.'

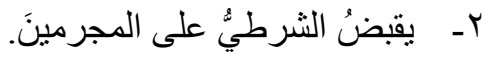

2- 'The policeman m.s. catches m.s. the criminal.'

$$
\text { r- يبكي الصغيرُ عندَ الثعورِ بالجوع. }
$$

3- 'The baby m.s. cries m.s. when feeling hungry.'

$$
\text { ع- ـ بصمُ المهندسُ المبانيَ باتقانٍ. }
$$

4- 'The engineer m.s. designs m.s. the buildings elaborately.'

$$
\text { هـ - يسيرُ القطارُ بسر عةٍ كبيرةٍ. }
$$

5- 'The train m.s. moves m.s. with a great speed.'

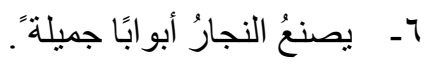

6- 'The carpenter m.s. makes m.s. beautiful doors.'

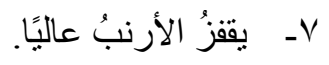

7- 'The rabbit m.s. jumps m.s. high.'

\section{Grammatical: Feminine verb - Feminine subject, Present tense}

$$
\text { 1- تحبُّ هندُ قر اعةً الشعرِ. }
$$

1- 'Hend f.s. likes f.s. reading poetry.'

$$
\text { r - تفضلُ ليلى مشاهدةً الأفلامِ في المنزلِ. }
$$

2- 'Laila f.s. prefers f.s. watching movies at home.' 


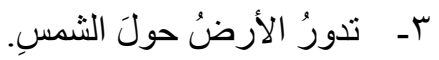

3- 'The earth f.s. orbits f.s. aroun the sun.'

$$
\text { ع- ـتسلقُ القطةُ الاشجارَ بمهارةٍ . }
$$

4- 'The cat f.s. climbs f.s. the trees skillfully.'

$$
\text { هـ ـ تأكلُ أختي العشاءَ مبكرًا كلَّ ليلةٍ. }
$$

5- 'My sister f.s. eats f.s. the dinner early every night.'

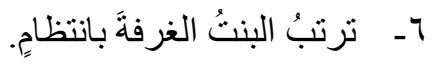

6- 'The girl f.s. clears f.s. up the room regularly.'

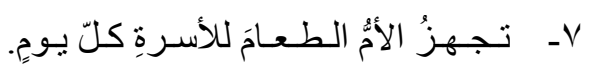

7- 'The mother f.s. prepares f.s. the food for the family every day.'

\section{Ungrammatical: Masculine verb - Feminine subject, Past tense}

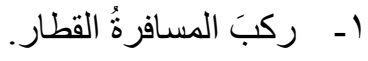

1- 'The passenger f.s. rode m.s. the train.'

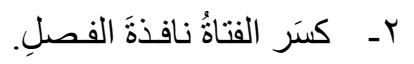

2- 'The girl f.s. broke m.s. the class's window.'

$$
\text { بـ - أقلعَ الطائرةُُ في الوقتِ المحددِ. }
$$

3- 'The plane f.s. took m.s. of on time.'

$$
\text { ع- ـ هربَ الدجاجةُ خوفًا من التُعلب. }
$$

4- 'The chicken f.s. escaped m.s. for fear of the fox.'

$$
\text { هـ - سقَ السبورةٌُ على الأرضِ. }
$$

5- 'The blackboard f.s. fell m.s. to the floor.'

$$
\text { 7- نَسيَ عائشةُ كتابَ النحو. }
$$

6- 'Aisha f.s. forgot m.s. the grammar book.'

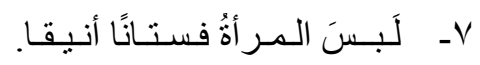

7- 'The woman f.s wore m.s. a stylish dress.' 


\section{Ungrammatical: Feminine verb -Masculine subject, Past tense}

$$
\text { ا - ـ ـ صادت الأســُ غزالاً. }
$$

1- 'The lion m.s. hunted f.s. a deer.'

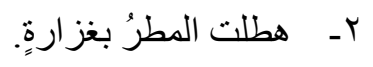

2- 'The rain m.s. teemed f.s. down heavily.'

$$
\text { r- أنقذت رجل الإطفاء المصابين. }
$$

3- 'The fireman m.s. rescued f.s. the injured.'

$$
\text { عـ ـ سجّلت اللاعب رقمًا قياسيًا جديدًا. }
$$

4- 'The player m.s. set f.s. a new record.'

$$
\text { هـ انتهَت الخادم من تنظيف المنزل. }
$$

5- 'The manservant m.s. finished f.s. from cleaning the house.'

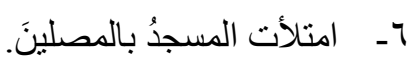

6- 'The mosque m.s. filled f.s. with worshipers.'

$$
\text { V- - ألَفت الكاتبُ رواية شيّقة. }
$$

7- 'The writer m.s. composed f.s. an interesting novel'.

\section{Ungrammatical: Masculine verb - Feminine subject, Present tense}

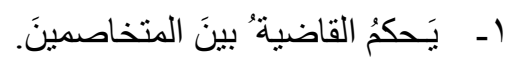

1- 'The judge f.s. decides m.s. between adversaries.'

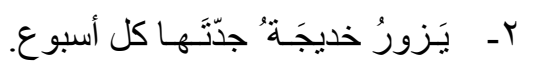

2- 'Khadija f.s. visits m.s. her grandmother every week.

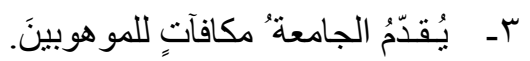

3- 'The university f.s. offers m.s. rewards for the talented.

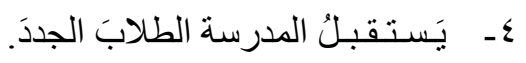

4- 'The school f.s. welcomes m.s. the new students.'

$$
\text { هـ ـ يُصدّرُ المملكةُ العربيةُ السعوديةٌ النفط. }
$$

5- 'The kingdom f.s. of Saudi Arabia exports m.s. the petroleum.' 


$$
\text { 7- يَطيرُ الحمامةُ لمسافاتٍ طويلةٍ. }
$$

6- 'The pigeon f.s. flies m.s. for long distance.'

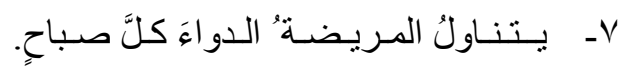

7- 'The patient f.s. takes m.s. the medication every

\section{Ungrammatical: Feminine verb -Masculine subject, Present tense}

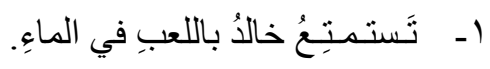

1- 'Khalid m.s. enjoys f.s. playing in the water.'

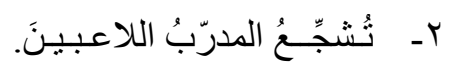

2- 'The coach m.s. encourages f.s. the players.'

$$
\text { بـ - تُرُ اجعُ المحاسبُ المستندات. }
$$

3- 'The accountant m.s. reviews f.s. the documents.'

$$
\text { عـ ــ تَصَومُ المسلمُ شهرَ رمضانَ كاملاً. }
$$

4- 'The Muslim m.s. fasts f.s. the whole month of Ramadhan.'

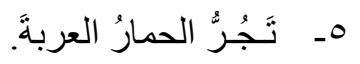

5- 'The donkey m.s. pulls f.s. the cart.'

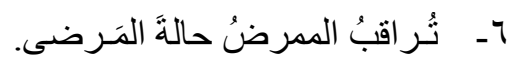

6- 'The nurse m.s. monitors f.s. the patients' status.'

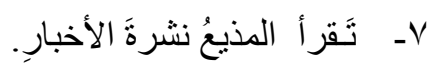

7- 'The broadcaster m.s. reads f.s. newsletter.'

\section{Grammatical Fillers}

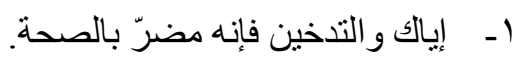

1- 'Beware of smoking, it is harmful to health'

$$
\text { r- المحاميانِ خسر ا القضية. }
$$

2- 'The lawyers lost the case.'

$$
\text { r- اللونُ الأخضرُ يشعرني بالر احة. }
$$

3- 'The green color makes me feel comfortable.' 


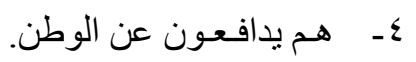

4- 'They are defending their homeland.'

$$
\text { 0- ـ لـو لا الكتابـة لضـاع معظم الـعلم. }
$$

5- 'Without writing, most knowledge would have been lost'.

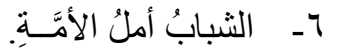

6- 'The youth is the hope of the nation.'

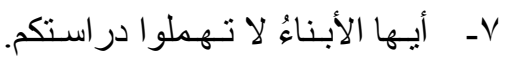

7- 'Dear children, do not neglect your studies.'

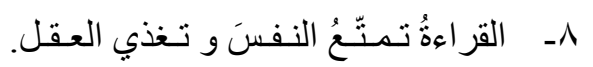

8- 'Reading enjoys yourself and benefits your mind'.

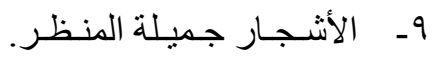

9- 'The trees are beautiful'.

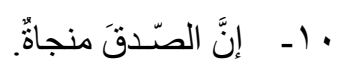

10 - 'Honest is the best policy.'

$$
\text { 11 - ـ الرياضةُ تنفيدُ القلبَّ و العضلات. }
$$

11- 'Sport benefits the heart and muscles.'

$$
\text { r ا - يسكُ الصقورُ في أعالي الجبالِ. }
$$

12- 'The falcons live in high mountains.'

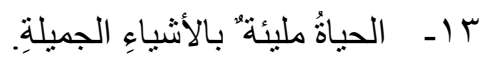

13- 'The life is full of good things.'

$$
\text { ع ا ـ الأسرةُ الصالحةُ هيَ أساسُ المجتمع الصالح. }
$$

14- 'The good family is the foundation of a good society.'

$$
\text { 10 - ـ الفلاحونَ يزر عونَ الأرضَ. }
$$

15- 'The farmers cultivate land.'

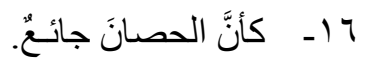

16- 'The horse seems hungry.'

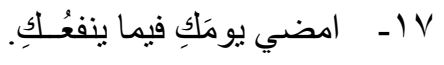

17- 'Spend your day in what will benefit you.' 


$$
\text { 11 إ- لا تغادروا أماكِنَكم حتى تسـعـوا الجرسَ. }
$$

18- 'Do not leave your places until you hear the ring.'

$$
\text { 19 - صديقي ســسافـرُ إلى مصر بعد أسبوعٍ. }
$$

19- 'My friend will go to Egypt next week'.

$$
\text { • - ـ أتعرفُ تللكَ المكتبةَ التي في أعلى الثـار ع؟ }
$$

20- 'Do you know that library which is at the top of the street?'

$$
\text { ا ا - - كانت السماءُ صافيةً يومَ أمس. }
$$

21- 'The sky was clear yesterday.'

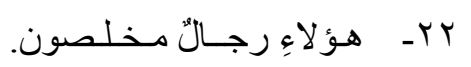

22- 'These men are sincere.'

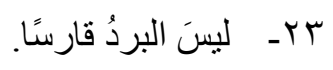

23- 'The cold is not severe.'

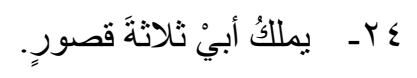

24- 'My father owns three palaces.'

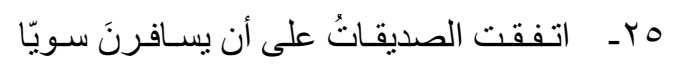

25- 'The friends agreed to travel together.'

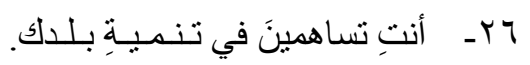

26- 'You contribute in your country's development.'

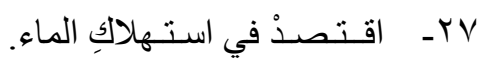

27- 'Economize in water consumption.'

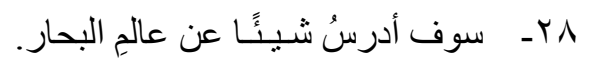

28- 'I will study something about the sea world.'

\section{Ungrammatical Fillers}

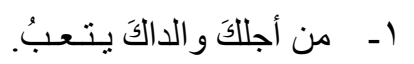

1- 'Your parents get tired for you.'

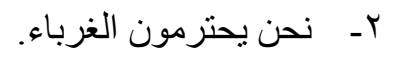

2- 'We respect strangers'. 


$$
\text { بـ يسقي المزارعُ الأزهـارَ الذي في الحديقة. }
$$

3- 'The gardener irrigate the flowers that are in the garden.'

$$
\text { ع - أنتن مهندستان بار عتان. }
$$

4- 'You are skillful engineers'

$$
\text { 0ـ - ل لن شارك أحمد في المسابقة. }
$$

5- 'Ahmed will not participate in the competition.'

$$
\text { 7- تنتـج البقرةُ الأبيضُ كمية كبيرة من الحليب. }
$$

6- 'The white cow produces large amount of milk.'

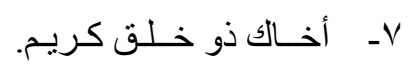

7- 'Your brother has good manners.'

$$
\text { 1- يُحافظ الطلابُ إلى نظافةِ الفصلِ. }
$$

8- 'The students maintain the class cleanness.'

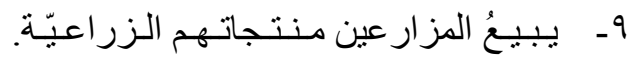

9- 'Farmers sell their corps.'

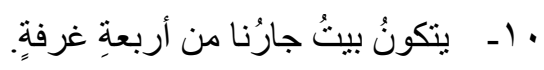

10- 'Our neighbor's house consists of four rooms.'

$$
\text { | - استـمعنا إلى قصيدتان جميلتان. }
$$

11 - 'We listened to two beautiful poems.'

$$
\text { r ا - سأشتـري ثوبًا سـوداء. }
$$

12- 'I will buy a black dress.'

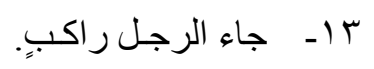

13- 'The man came by car'.

$$
\text { ع ا ـ انتظرَ المعلمُ حتى يستعدانِ التلميذانِ. }
$$

14- 'The teacher waited for student to be ready'.

$$
10 \text { - ـما يعمـلون في الصـحافـة. }
$$

15- 'They are working in the press.'

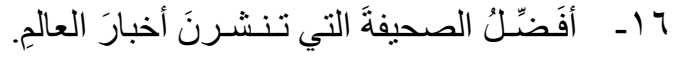

16- 'I like the newspapers that publish the world news.' 


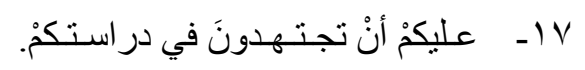

17- 'You should work hard in your studies'.

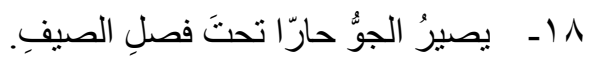

18- 'The whether becomes hot in the summer.'

$$
9 \text { ا ـ ـ اللوحاتُ الذينَ في المعرضِ غاليةُ الثمنِ. }
$$

19- 'The paintings, which are in the exhibition, are expensive.'

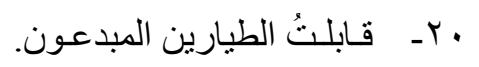

20- 'I met nice pilots'.

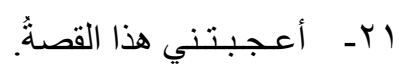

21 - 'This story amazed me.'

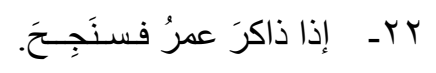

22- 'If Omar studies, he will pass.'

$$
\text { بr - مانَ الضيوفُ مسرورًا. }
$$

23- 'The guests were happy.'

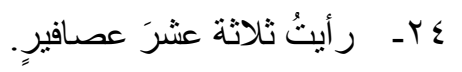

24- 'I saw thirteen sparrows.'

$$
\text { هب - وصـلَ الرجـلُ الذي كرمهـم المديـرُ. }
$$

25- 'The man, who was lionized by the boss, arrived.'

$$
\text { جr- ستلقي المحاضرةَ هـؤلاعِ الأستاذةُ. }
$$

26- 'This professor is going to give the talk.'

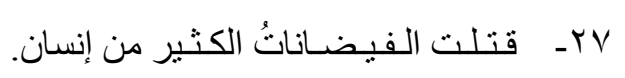

27- 'The floods destroyed a lot of people.'

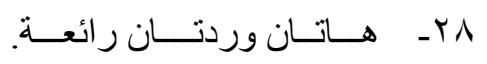

28- 'These two flowers are wonderful'. 


\section{Appendix B: Sentence Completion Task 1 (Missing verb)}

\section{Masculine - Past tense}

1- The man to the mall last night.

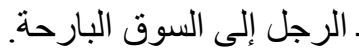

2- The student the Arabic

r---_الطالب في اختبار اللغة العربية. language exam.

3- The team the trophy.

الفريق بكأس البطولة.

المعلم الدرس. $-\varepsilon$

4- The teacher the lesson.

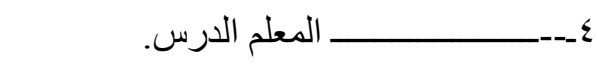

5- The boy a letter to his

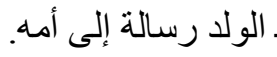
mother.

6- The player behind the ball.

ــاعب خلف الكرة. $-7$

7- The Imam the chapter of

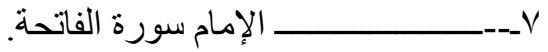
Alfatihah.

8- Mohammad in his country

إلى بلده سالما. $---\wedge$ safely.

\section{Feminine - Past tense}

1- Fatimah a nice dress.

فاطمة فستانا جميلا.

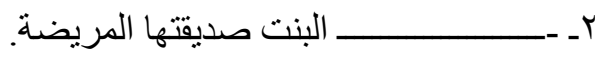
$-r$

2- The girl her sick friend.

3- The woman delicious food. المر أة طعاما لذيذا. $-\Gamma^{2}$

4- The cat on the wall. القطة من فوق الجدار. $-\varepsilon$

5- The plane at 4 o'clock. 
6- The principal the outstanding students.

7- The apple on the ground.

8- The mother her daughter via the phone.

\section{Masculine - Present tense}

1- Khalid to sleep early.

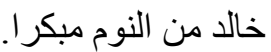

2- The businessman helping the needy people.

3- The airport hundreds of passengers every day.

4- The policeman car traffic

5- The worker his work perfectly.

6- The rain heavily.

7- The sick man from stomachache.

8- Omar reading stories.

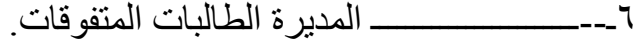

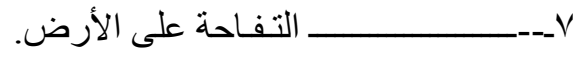

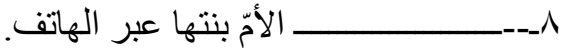

"----_المطار مئات المسافرين كل يوم.

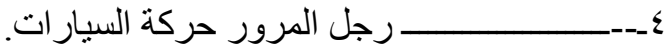
$-7$

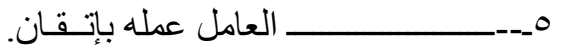

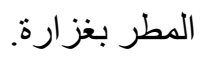

المريض من ألم في المعدة. $--\gamma$
A

\section{Feminine - Present tense}

1- The school a variety of الـَـدرَسة نشاطات مختلفة للطلاب. $--1$ activities for students.

2- Aishah__ her grandmother every Wednesday.

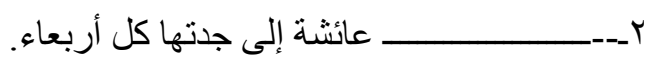


3- The magazine the society

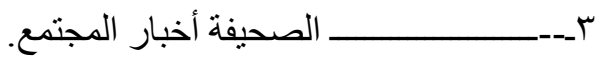
news.

4- The library its doors for

$$
\text { المكتبة أبو ابها للقر اء. }
$$
$-\varepsilon$ readers.

5- Hind in the city of Riyadh.

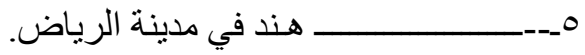

6- The polite girl her parent.

7

7- The university tens of

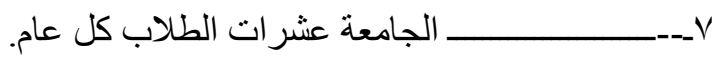
people every year.

8- My sister the Arabic أختي اللغة العربية بطلاقة. language fluently. 


\section{Appendix C: Sentence Completion Task 2 (Missing noun)}

\section{Masculine (Past tense)}

1- __ grieved the death of his friend.

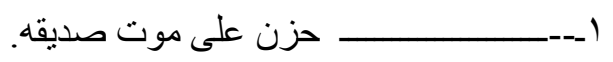

$2-$ was absent due to illness.

$$
\text { ـــ---r }
$$

3came on time.

حضر في الوقت المحدد.

4- __ recited a beautiful poem.

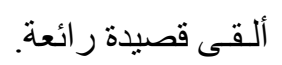
$--\varepsilon$

$5-$ sang with a nice voice.

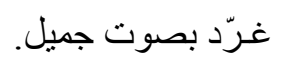

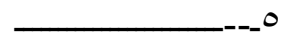

6found his wallet.

$$
\text { وجد محفظة نـقوده. }
$$

7devoured a small deer.

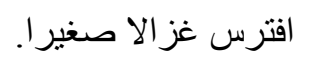

8- __ listened to his father's advice.

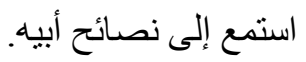
$--1$

\section{Feminine (Past tense)}

1-___ tidied her room before going out.

$$
\text { رتّبَتَت غرفتها قبل أن تخرج. }
$$

$2-$

finished doing her homework.

$$
\text { انتـهَت من أداء واجباتها. }
$$

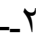

3filled with guests.

$$
\text { امنلأَت بالحاضرين. }
$$
$--\varepsilon$

4was happy to be in first place.

فرحَت لحصولها على المركز الأول. $--r$

$5-$ flew high.

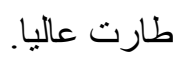


6painted a wonderful artwork.

رسمَـت لوحسة جميلة. $-7$

7broke the class window.

كسرت نافذة الفصل. $---{ }^{-}$

8ran very quickly.

انطلـََت بسر عة عالية. ---ᄉ

\section{Masculine (Present tense)}

1- __ listens to the radio every morning.

بسنمع إلى الإذاعة كل صباح.

2exercises on a regular basis

يمارس الرياضة بانتظام. $--r$

3prescribes medicine to the sick people.

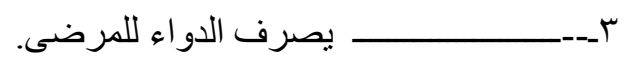

4raises birds on his farm.

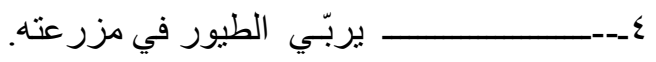

5- works in his father's store.

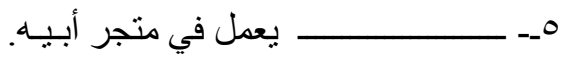

6- ___ drinks many cups of coffee every morning.

يشرب الكثير من القهوة كل يوم. $--7$

7watches the sunset every day.

ير اقب غروب الثمس كل يوم. $---{ }^{-}$

8accommodates up to forty people.

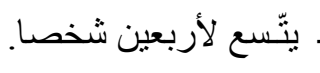

\section{Feminine (Present tense)}

$1-$ takes care of her children.

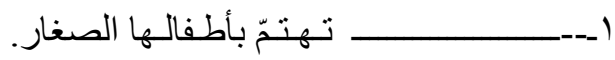


2announces new jobs every year.

$3-$ students.

4- __ buys new shoes every month.

5- __ receives her mail every Monday.

6drives her car to work.

7memorizes many old poems.

8fears the darkness. explains the topic for the

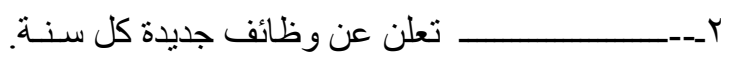

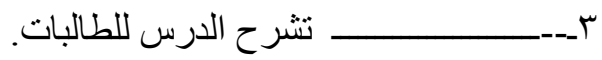

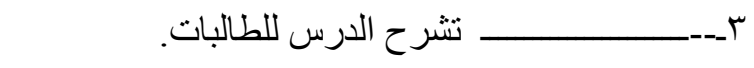

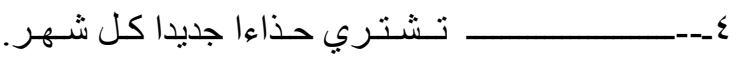

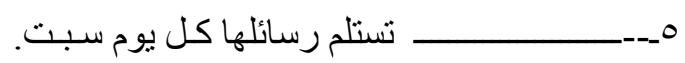
تقود سيارتها إلى العمل. $-7$

تحفظ الكثير من الأشعار القديمة. $---Y$

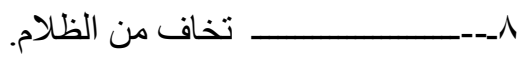


Appendix D: Picture Description Task

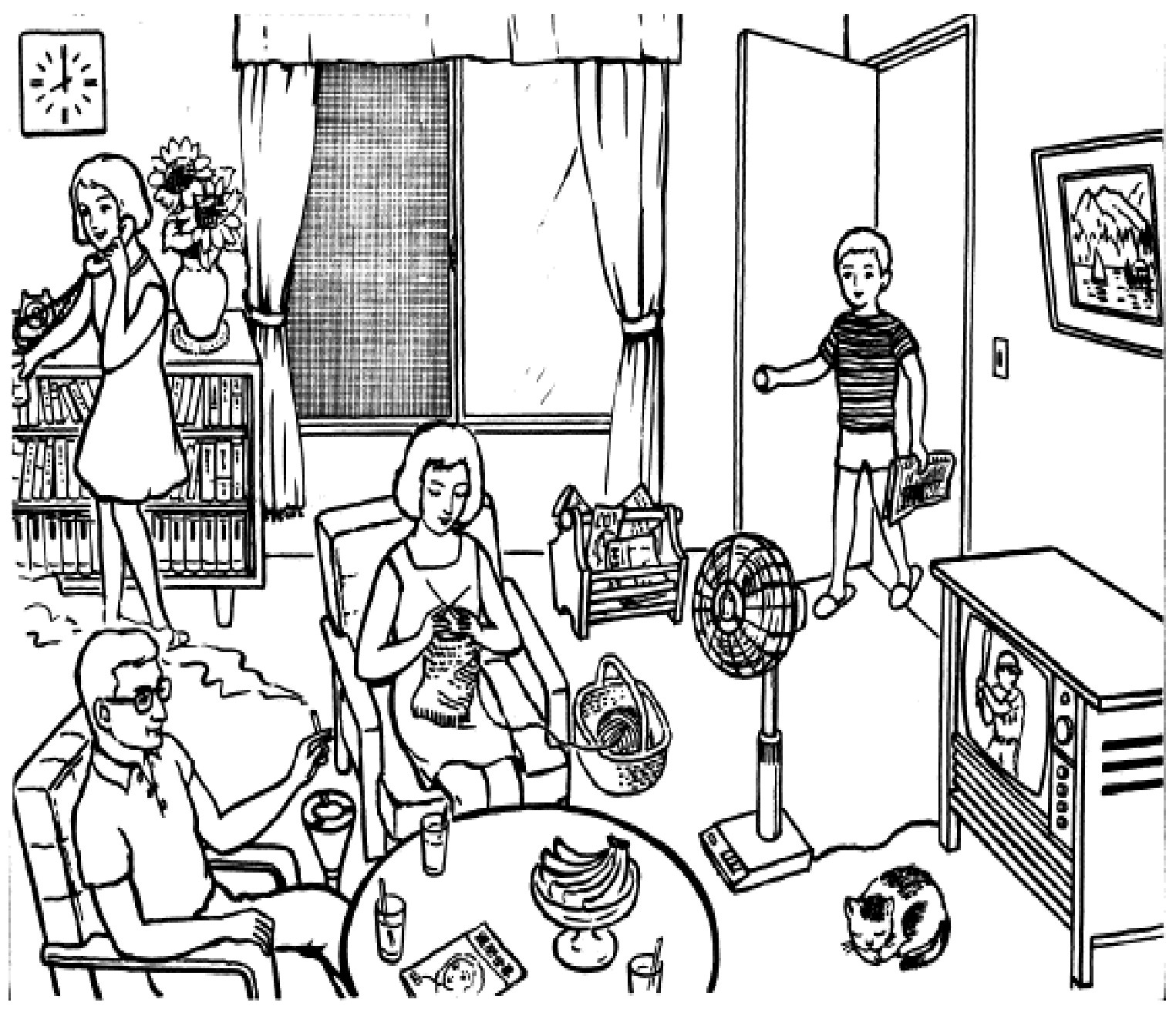


Appendix D Cont'd

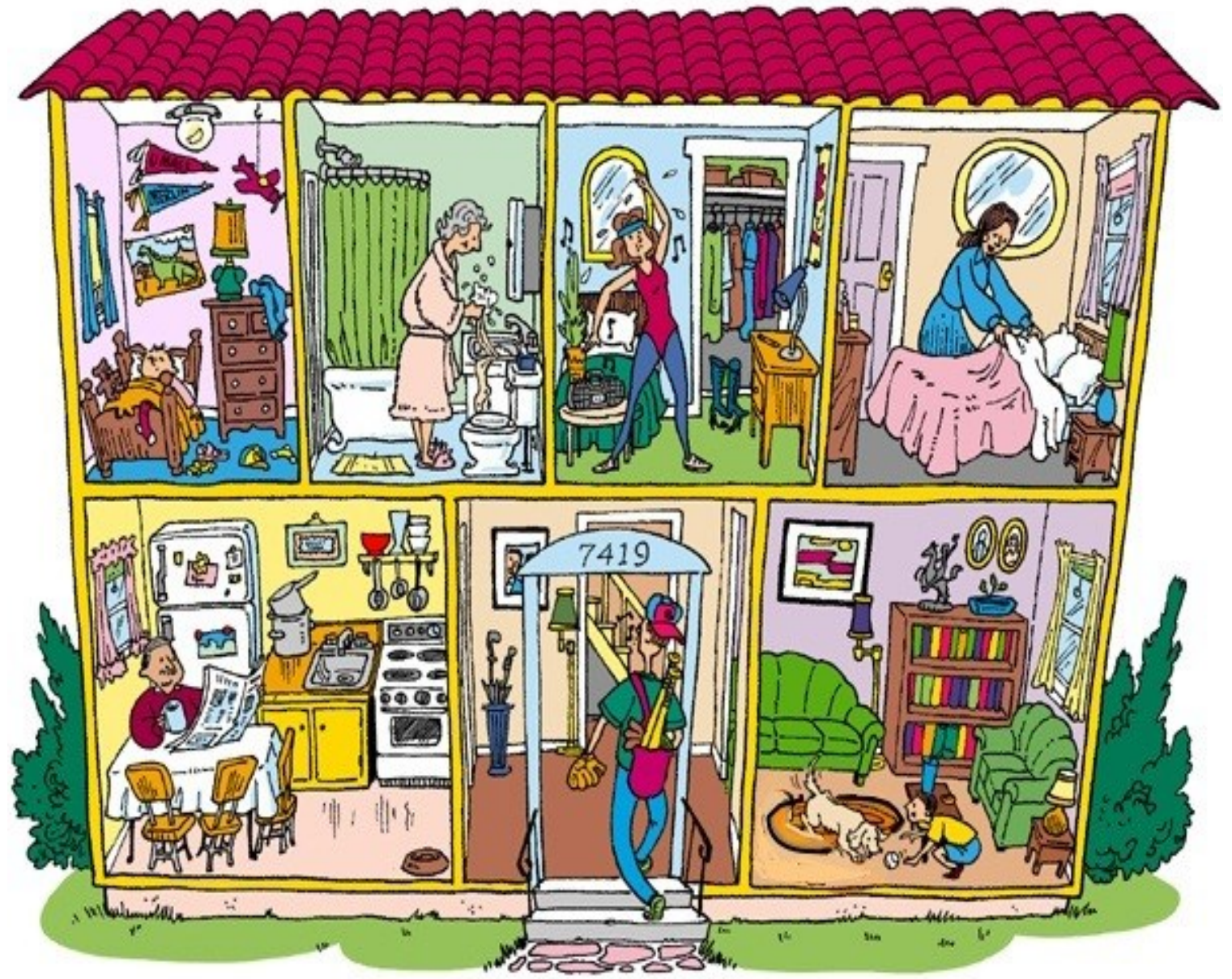


Appendix D Cont'd

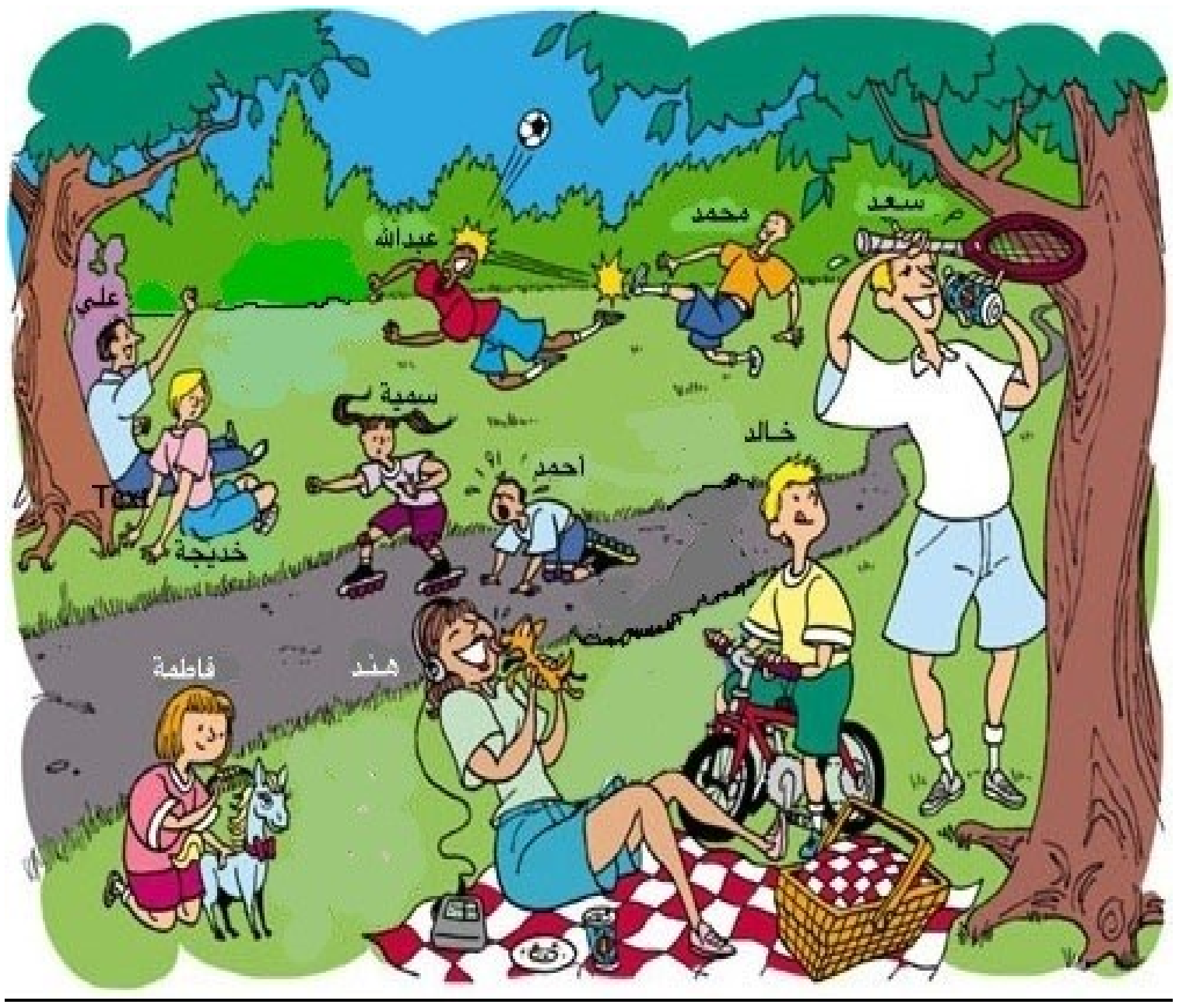


Appendix D Cont'd

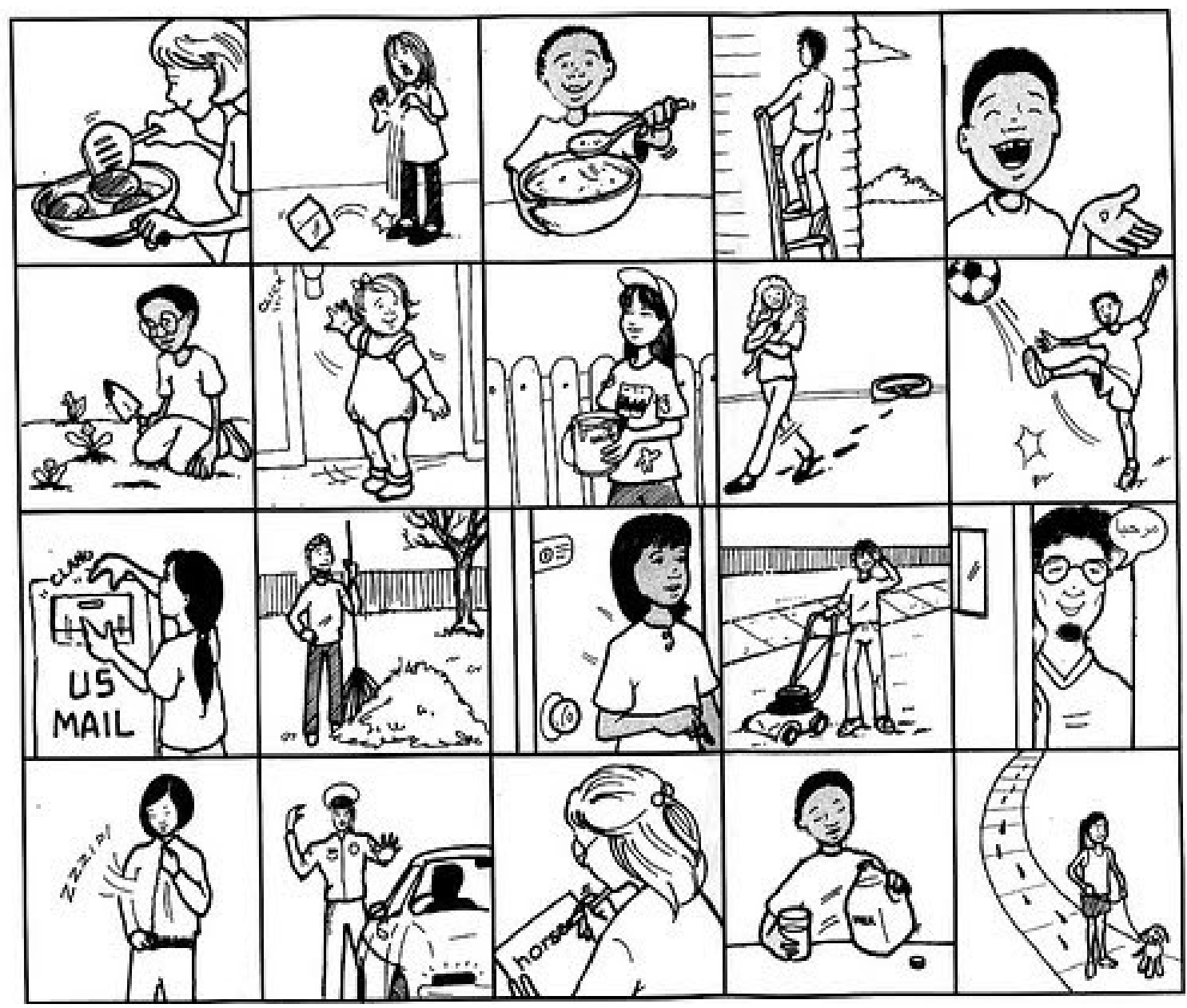


Appendix E: Background Questionnaire (This was translated from Arabic)

\section{Questionnaire}

Date: / / 2013

Please answer the following questions:

1- What is your date of birth?

2- What is your mother tongue?

3- What other languages do you speak?

- .............. (Proficiency level: $\square$ Beginner $\square$ Intermediate $\square$ Advanced Very advanced)

- $\quad . . . . . . . . . . .$. (Proficiency level: $\square$ Beginner $\square$ Intermediate $\square$ Advanced Very advanced)

- .............. (Proficiency level: $\square$ Beginner $\square$ Intermediate $\square$ Advanced Very advanced)

4- What is your current school level?

5- How many months/years did you study Arabic?

6- Have you been in any Arabic-speaking country?

7- What was your age when you first started learning Arabic?

8- How long have you been in Saudi Arabia?

9- Why are you studying Arabic?

10-What are your current strengths and weaknesses in the different skills of Arabic? 
Appendix F: Participants' Results on Proficiency Test

\begin{tabular}{|c|c|c|}
\hline \multicolumn{3}{|c|}{ Reading Proficiency Test } \\
\hline $\begin{array}{c}\text { Arabic } \\
\text { Learners }\end{array}$ & $\begin{array}{c}\text { Raw Score } \\
\text { (40) }\end{array}$ & Percentage \\
\hline AL17 & 39 & 97.5 \\
\hline AL38 & 39 & 97.5 \\
\hline AL7 & 38 & 95.0 \\
\hline AL18 & 37 & 92.5 \\
\hline AL19 & 37 & 92.5 \\
\hline AL30 & 37 & 92.5 \\
\hline AL6 & 36 & 90.0 \\
\hline AL22 & 36 & 90.0 \\
\hline AL24 & 36 & 90.0 \\
\hline AL2 & 35 & 87.5 \\
\hline AL8 & 35 & 87.5 \\
\hline AL9 & 35 & 87.5 \\
\hline AL23 & 35 & 87.5 \\
\hline AL40 & 35 & 87.5 \\
\hline AL16 & 34 & 85.0 \\
\hline AL20 & 34 & 85.0 \\
\hline AL31 & 34 & 85.0 \\
\hline AL39 & 34 & 85.0 \\
\hline AL3 & 33 & 82.5 \\
\hline AL32 & 33 & 82.5 \\
\hline AL13 & 32 & 80.0 \\
\hline AL25 & 31 & 77.5 \\
\hline AL10 & 30 & 75.0 \\
\hline AL29 & 30 & 75.0 \\
\hline AL11 & 29 & 72.5 \\
\hline AL36 & 29 & 72.5 \\
\hline AL37 & 29 & 72.5 \\
\hline AL5 & 28 & 70.0 \\
\hline AL12 & 28 & 70.0 \\
\hline AL33 & 27 & 67.5 \\
\hline AL15 & 26 & 65.0 \\
\hline AL1 & 25 & 62.5 \\
\hline AL4 & 25 & 62.5 \\
\hline AL26 & 25 & 62.5 \\
\hline AL28 & 25 & 62.5 \\
\hline AL34 & 24 & 60.0 \\
\hline AL35 & 24 & 60.0 \\
\hline AL14 & 23 & 57.5 \\
\hline AL21 & 23 & 57.5 \\
\hline AL27 & 22 & 55.0 \\
\hline Mean & 31.2 & 77.94 \\
\hline
\end{tabular}

\begin{tabular}{|c|c|c|}
\hline \multicolumn{3}{|c|}{ Reading Proficiency Test } \\
\hline $\begin{array}{c}\text { Native } \\
\text { Speakers }\end{array}$ & $\begin{array}{c}\text { Raw Score } \\
\mathbf{( 4 0 )}\end{array}$ & Percentage \\
\hline NS5 & 40 & 100.0 \\
\hline NS8 & 40 & 100.0 \\
\hline NS11 & 40 & 100.0 \\
\hline NS12 & 40 & 100.0 \\
\hline NS13 & 40 & 100.0 \\
\hline NS14 & 40 & 100.0 \\
\hline NS15 & 40 & 100.0 \\
\hline NS1 & 39 & 97.5 \\
\hline NS3 & 39 & 97.5 \\
\hline NS6 & 39 & 97.5 \\
\hline NS9 & 39 & 97.5 \\
\hline NS10 & 39 & 97.5 \\
\hline NS2 & 38 & 95.0 \\
\hline NS7 & 38 & 95.0 \\
\hline NS4 & 37 & 92.5 \\
\hline Mean & $\mathbf{3 9 . 2}$ & $\mathbf{9 8 . 0}$ \\
\hline
\end{tabular}




\section{Appendix G: Participants' Results on Grammaticality Judgment Task}

\begin{tabular}{|c|c|c|}
\hline \multicolumn{3}{|c|}{ Grammaticality Judgment Task } \\
\hline $\begin{array}{c}\text { Arabic } \\
\text { Learners }\end{array}$ & $\begin{array}{c}\text { Raw Score } \\
(56)\end{array}$ & Percentage \\
\hline AL34 & 54 & 96.4 \\
\hline AL37 & 54 & 96.4 \\
\hline AL38 & 54 & 96.4 \\
\hline AL3 & 53 & 94.6 \\
\hline AL24 & 53 & 94.6 \\
\hline AL31 & 53 & 94.6 \\
\hline AL33 & 53 & 94.6 \\
\hline AL40 & 53 & 94.6 \\
\hline AL2 & 52 & 92.9 \\
\hline AL8 & 52 & 92.9 \\
\hline AL17 & 52 & 92.9 \\
\hline AL6 & 51 & 91.1 \\
\hline AL18 & 51 & 91.1 \\
\hline AL19 & 51 & 91.1 \\
\hline AL30 & 51 & 91.1 \\
\hline AL39 & 51 & 91.1 \\
\hline AL5 & 49 & 87.5 \\
\hline AL10 & 49 & 87.5 \\
\hline AL16 & 49 & 87.5 \\
\hline AL23 & 49 & 87.5 \\
\hline AL28 & 49 & 87.5 \\
\hline AL7 & 48 & 85.7 \\
\hline AL25 & 48 & 85.7 \\
\hline AL36 & 48 & 85.7 \\
\hline AL32 & 47 & 83.9 \\
\hline AL35 & 47 & 83.9 \\
\hline AL27 & 46 & 82.1 \\
\hline AL26 & 45 & 80.4 \\
\hline AL9 & 43 & 76.8 \\
\hline AL11 & 43 & 76.8 \\
\hline AL15 & 43 & 76.8 \\
\hline AL29 & 43 & 76.8 \\
\hline AL20 & 40 & 71.4 \\
\hline AL21 & 37 & 66.1 \\
\hline AL22 & 36 & 64.3 \\
\hline AL13 & 34 & 60.7 \\
\hline AL4 & 32 & 57.1 \\
\hline AL12 & 31 & 55.4 \\
\hline AL1 & 17 & 30.4 \\
\hline AL14 & 16 & 28.6 \\
\hline Mean & 45.7 & 82.0 \\
\hline
\end{tabular}

\begin{tabular}{|c|c|c|}
\hline \multicolumn{3}{|c|}{ Grammaticality Judgment Task } \\
\hline $\begin{array}{c}\text { Native } \\
\text { Speakers }\end{array}$ & $\begin{array}{c}\text { Raw Score } \\
\text { (56) }\end{array}$ & Percentage \\
\hline NS1 & 56 & 100 \\
\hline NS3 & 56 & 100 \\
\hline NS4 & 56 & 100 \\
\hline NS9 & 56 & 100 \\
\hline NS10 & 56 & 100 \\
\hline NS5 & 55 & 98.2 \\
\hline NS6 & 55 & 98.2 \\
\hline NS8 & 55 & 98.2 \\
\hline NS11 & 55 & 98.2 \\
\hline NS14 & 55 & 98.2 \\
\hline NS15 & 55 & 98.2 \\
\hline NS7 & 54 & 96.4 \\
\hline NS12 & 54 & 96.4 \\
\hline NS13 & 54 & 96.4 \\
\hline NS2 & 54 & 96.4 \\
\hline Mean & $\mathbf{5 5 . 1}$ & $\mathbf{9 8 . 3 3}$ \\
\hline
\end{tabular}


Appendix H: Participants' Results on Sentence Completion Task 1

\begin{tabular}{|c|c|c|}
\hline \multicolumn{3}{|c|}{ Sentence Completion Task 1} \\
\hline $\begin{array}{c}\text { Arabic } \\
\text { Learners }\end{array}$ & $\begin{array}{c}\text { Raw Score } \\
\text { (32) }\end{array}$ & Percentage \\
\hline AL10 & 32 & 100 \\
\hline AL19 & 32 & 100 \\
\hline AL20 & 32 & 100 \\
\hline AL27 & 32 & 100 \\
\hline AL29 & 32 & 100 \\
\hline AL33 & 32 & 100 \\
\hline AL34 & 32 & 100 \\
\hline AL36 & 32 & 100 \\
\hline AL5 & 31 & 96.9 \\
\hline AL7 & 31 & 96.9 \\
\hline AL9 & 31 & 96.9 \\
\hline AL12 & 31 & 96.9 \\
\hline AL18 & 31 & 96.9 \\
\hline AL30 & 31 & 96.9 \\
\hline AL32 & 31 & 96.9 \\
\hline AL37 & 31 & 96.9 \\
\hline AL3 & 30 & 93.8 \\
\hline AL6 & 30 & 93.8 \\
\hline AL8 & 30 & 93.8 \\
\hline AL16 & 30 & 93.8 \\
\hline AL17 & 30 & 93.8 \\
\hline AL25 & 30 & 93.8 \\
\hline AL28 & 30 & 93.8 \\
\hline AL31 & 30 & 93.8 \\
\hline AL38 & 30 & 93.8 \\
\hline AL39 & 30 & 93.8 \\
\hline AL40 & 30 & 93.8 \\
\hline AL24 & 29 & 90.6 \\
\hline AL21 & 28 & 87.5 \\
\hline AL22 & 28 & 87.5 \\
\hline AL35 & 28 & 87.5 \\
\hline AL14 & 26 & 81.3 \\
\hline AL11 & 25 & 78.1 \\
\hline AL23 & 25 & 78.1 \\
\hline AL26 & 25 & 78.1 \\
\hline$\overline{\text { AL2 }}$ & 24 & 75.0 \\
\hline AL4 & 22 & 68.8 \\
\hline AL15 & 19 & 59.4 \\
\hline AL13 & 17 & 53.1 \\
\hline AL1 & 16 & 50.0 \\
\hline Mean & 28.7 & 90.0 \\
\hline
\end{tabular}

\begin{tabular}{|c|c|c|}
\hline \multicolumn{3}{|c|}{ Sentence Completion Task 1 } \\
\hline $\begin{array}{c}\text { Native } \\
\text { Speakers }\end{array}$ & $\begin{array}{c}\text { Raw Score } \\
\text { (32) }\end{array}$ & Percentage \\
\hline NS2 & 32 & 100 \\
\hline NS3 & 32 & 100 \\
\hline NS5 & 32 & 100 \\
\hline NS6 & 32 & 100 \\
\hline NS7 & 32 & 100 \\
\hline NS8 & 32 & 100 \\
\hline NS9 & 32 & 100 \\
\hline NS10 & 32 & 100 \\
\hline NS11 & 32 & 100 \\
\hline NS12 & 32 & 100 \\
\hline NS13 & 32 & 100 \\
\hline NS14 & 32 & 100 \\
\hline NS1 & 31 & 96.9 \\
\hline NS15 & 31 & 96.9 \\
\hline NS4 & 30 & 93.8 \\
\hline Mean & $\mathbf{3 1 . 7}$ & $\mathbf{9 9 . 0}$ \\
\hline
\end{tabular}


Appendix I: Participants' Results on Sentence Completion Task 2

\begin{tabular}{|c|c|c|}
\hline \multicolumn{3}{|c|}{ Sentence Completion Task 2} \\
\hline $\begin{array}{c}\text { Arabic } \\
\text { Learners }\end{array}$ & $\begin{array}{c}\text { Raw Score } \\
\text { (32) }\end{array}$ & Percentage \\
\hline AL8 & 32 & 100 \\
\hline AL17 & 32 & 100 \\
\hline AL19 & 32 & 100 \\
\hline AL20 & 32 & 100 \\
\hline AL24 & 32 & 100 \\
\hline AL28 & 32 & 100 \\
\hline AL2 & 31 & 96.9 \\
\hline AL3 & 31 & 96.9 \\
\hline AL7 & 31 & 96.9 \\
\hline AL9 & 31 & 96.9 \\
\hline AL10 & 31 & 96.9 \\
\hline AL13 & 31 & 96.9 \\
\hline AL14 & 31 & 96.9 \\
\hline AL16 & 31 & 96.9 \\
\hline AL21 & 31 & 96.9 \\
\hline AL25 & 31 & 96.9 \\
\hline AL29 & 31 & 96.9 \\
\hline AL30 & 31 & 96.9 \\
\hline AL31 & 31 & 96.9 \\
\hline AL38 & 31 & 96.9 \\
\hline AL18 & 30 & 93.8 \\
\hline AL22 & 30 & 93.8 \\
\hline AL23 & 30 & 93.8 \\
\hline AL26 & 30 & 93.8 \\
\hline AL33 & 30 & 93.8 \\
\hline AL34 & 30 & 93.8 \\
\hline AL36 & 30 & 93.8 \\
\hline AL37 & 30 & 93.8 \\
\hline AL39 & 30 & 93.8 \\
\hline AL40 & 30 & 93.8 \\
\hline AL4 & 29 & 90.6 \\
\hline AL6 & 29 & 90.6 \\
\hline AL12 & 29 & 90.6 \\
\hline AL32 & 29 & 90.6 \\
\hline AL5 & 28 & 87.5 \\
\hline AL11 & 27 & 84.4 \\
\hline AL1 & 25 & 78.1 \\
\hline AL35 & 23 & 71.9 \\
\hline AL27 & 22 & 68.8 \\
\hline AL15 & 21 & 65.6 \\
\hline Mean & 29.7 & 93.0 \\
\hline
\end{tabular}

\begin{tabular}{|c|c|c|}
\hline \multicolumn{3}{|c|}{ Sentence Completion Task 2 } \\
\hline $\begin{array}{c}\text { Native } \\
\text { Speakers }\end{array}$ & $\begin{array}{c}\text { Raw Score } \\
\text { (32) }\end{array}$ & Percentage \\
\hline NS1 & 32 & 100 \\
\hline NS2 & 32 & 100 \\
\hline NS3 & 32 & 100 \\
\hline NS4 & 32 & 100 \\
\hline NS5 & 32 & 100 \\
\hline NS6 & 32 & 100 \\
\hline NS7 & 32 & 100 \\
\hline NS9 & 32 & 100 \\
\hline NS10 & 32 & 100 \\
\hline NS11 & 32 & 100 \\
\hline NS13 & 32 & 100 \\
\hline NS14 & 32 & 100 \\
\hline NS15 & 32 & 100 \\
\hline NS8 & 31 & 96.9 \\
\hline NS12 & 31 & 96.9 \\
\hline Mean & $\mathbf{3 1 . 9}$ & $\mathbf{9 9 . 6}$ \\
\hline
\end{tabular}


Appendix J: Participants' Results on Picture Description Task

\begin{tabular}{|c|c|c|}
\hline \multicolumn{3}{|c|}{ Picture Description Task } \\
\hline Arabic Learners & Raw Score & Percentage \\
\hline AL3 & 34 & 100 \\
\hline AL6 & 38 & 100 \\
\hline AL8 & 39 & 100 \\
\hline AL12 & 40 & 100 \\
\hline AL16 & 40 & 100 \\
\hline AL21 & 40 & 100 \\
\hline AL22 & 42 & 100 \\
\hline AL37 & 40 & 100 \\
\hline AL38 & 41 & 100 \\
\hline AL36 & 41 & 97.6 \\
\hline AL30 & 40 & 95.2 \\
\hline AL14 & 38 & 95.0 \\
\hline AL2 & 37 & 94.9 \\
\hline AL18 & 37 & 94.9 \\
\hline AL20 & 35 & 94.6 \\
\hline AL19 & 33 & 94.3 \\
\hline AL13 & 32 & 94.1 \\
\hline AL24 & 38 & 92.7 \\
\hline AL27 & 37 & 92.5 \\
\hline AL35 & 36 & 92.3 \\
\hline AL7 & 34 & 91.9 \\
\hline AL28 & 38 & 90.5 \\
\hline AL34 & 37 & 90.2 \\
\hline AL5 & 34 & 89.5 \\
\hline AL11 & 32 & 88.9 \\
\hline AL31 & 36 & 87.8 \\
\hline AL17 & 34 & 87.2 \\
\hline AL10 & 34 & 85.0 \\
\hline AL39 & 32 & 84.2 \\
\hline AL33 & 29 & 74.4 \\
\hline AL23 & 27 & 73.0 \\
\hline AL26 & 30 & 71.4 \\
\hline AL15 & 22 & 57.9 \\
\hline Mean & 35.7 & 91.0 \\
\hline
\end{tabular}

\begin{tabular}{|c|c|c|}
\hline \multicolumn{3}{|c|}{ Picture Description Task } \\
\hline $\begin{array}{c}\text { Native } \\
\text { Speakers }\end{array}$ & $\begin{array}{c}\text { Raw } \\
\text { Score }\end{array}$ & Percentage \\
\hline NS1 & 43 & 100 \\
\hline NS2 & 43 & 100 \\
\hline NS3 & 43 & 100 \\
\hline NS4 & 43 & 100 \\
\hline NS5 & 43 & 100 \\
\hline NS6 & 43 & 100 \\
\hline NS7 & 43 & 100 \\
\hline NS8 & 43 & 100 \\
\hline NS9 & 43 & 100 \\
\hline NS10 & 43 & 100 \\
\hline NS11 & 43 & 100 \\
\hline NS12 & 43 & 100 \\
\hline NS13 & 43 & 100 \\
\hline NS14 & 43 & 100 \\
\hline NS15 & 43 & 100 \\
\hline Mean & $\mathbf{4 3}$ & $\mathbf{1 0 0}$ \\
\hline
\end{tabular}

